\title{
LA MODIFICACIÓN DE LOS DESLINDES \\ DEL DOMINIO PÚBLICO MARÍTIMO-TERRESTRE: \\ REFLEXIONES A LA LUZ DEL DERECHO \\ DE PROPIEDAD Y DE LA PROTECCIÓN \\ DE LA CONFIANZA LEGÍTIMA
}

\author{
María José Alonso MAS \\ Profesora Titular de Derecho Administrativo \\ Universidad de Valencia
}

\begin{abstract}
RESUMEN
El TS entiende viable la modificación del deslinde de costas, para incluir nuevos terrenos, aunque no haya habido cambios normativos ni físicos desde el deslinde anterior. Ello es cuestionable desde la perspectiva de la seguridad del tráfico inmobiliario, si no se acompaña en su caso de indemnizaciones por lesión de la legítima confianza. Además, es cuestionable la base legal de esta doctrina; lo que puede tener incidencia a efectos del Protocolo Adicional a la CEDH.
\end{abstract}

Palabras clave: deslinde de costas; derecho de propiedad; seguridad del tráfico inmobiliario; confianza legítima; Registro de la Propiedad.

\begin{abstract}
Highest Court considers available to modify littoral bounds, including new lands into public property, although there are no physical nor normative changes. This position is questionable due to security in land trade, at least if damaged receive no indemnification. Besides, this position is doubtfully adequate to Littoral Spanish Act; and this may be relevant considering Human Rights European Court jurisprudence.
\end{abstract}

Key words: littoral bounds; property; land trade security; legitimate trust; Property Registration. 


\section{SUMARIO}

I. INTRODUCCIÓN.-II. LA POSICIÓN DE LA SALA TERCERA SOBRE LA POSIBILIDAD DE MODIFICACIÓN PERMANENTE DE LOS DESLINDES DEL DOMINIO PÚBLICO MARÍTIMOTERRESTRE.- III. CRÍTICA PRELIMINAR A LOS ARGUMENTOS UTILIZADOS POR EL TS: 1. Sobre el carácter "declarativo" de los deslindes de costas. 2. Contenido y efectos del deslinde de costas. 3. La doctrina de los actos propios. 4. La discutible base legal de la "complementación" de los deslindes que adolecen de errores técnicos. 5. El procedimiento de revisión del previo deslinde que resulta incompleto como consecuencia de un error técnico de la Administración.-IV. LAS RELACIONES ENTRE DESLINDE Y REgistro de LA PROPIEDAd EN LA NUEVA NORMATIVA DE COSTAS.V. PROPIEDAD, SEGURIDAD JURÍDICA Y CONFIANZA LEGÍTIMA COMO LÍMITES A LA POSIBILIDAD DE «COMPLEMENTACIÓN» DE LOS DESLINDES YA PRACTICADOS: 1 . El derecho de propiedad y su protección registral como límites a la posibilidad de revisión permanente de los deslindes de costas: A) Consideración preliminar: ¿es suficiente la concesión compensatoria como indemnización? B) La incidencia de la protección registral de la propiedad a la luz de la jurisprudencia del TEDH. C) La exigencia de indemnización integral en los casos de expropiación ilícita. 2. La protección de la confianza legítima como límite a la modificación de los deslindes.-VII. Posibles SOluciones: EN PARTICULAR, LA REVISIÓN DE OFICIO DEL DESLINDE PREVIO O LA DETERMINACIÓN DE LA INDEMNIZACIÓN EN EL ACTO QUE RESUELVE EL PROCEDIMIENTO DE MODIFICACIÓN: 1. El deber jurídico de soportar el daño causado por ciertos actos administrativos ilegales: una crítica a la doctrina del margen de tolerancia: A) Consideraciones generales. B) La distinción entre los daños causados por el acto anulado y los daños causados por la anulación del acto. 2. El procedimiento para la determinación de la indemnización.--VII. CONCLUSIONES.

\section{INTRODUCCIÓN}

Conforme al artículo 13 LC, la aprobación de los deslindes del demanio marítimo-terrestre, a diferencia de los ordinarios, tiene efectos jurídico-reales sobre la propiedad, así como efectos rectificatorios de las inscripciones registrales ${ }^{1}$. Para la STC 149/91, ello es conforme con la

1 Vid. M. García Pérez (2004), «El deslinde de las costas», Anuario de la Facultad de Derecho de la Universidad de La Coruña, 8, págs. 391 ss.; S. GonZÁLEZ-VARAs IBáñez (1995), El deslinde de las costas, Marcial Pons, Madrid; F. Meco Tébar (1998), El deslinde de las costas: efectos jurídico civiles, Tirant lo Blanch, Valencia; B. Rodríguez Chaves MimBrero (2010), «Bienes de dominio público marítimo terrestre y deslindes», en La Ley de costas en la jurisprudencia, Ministerio de Medio Ambiente y del Medio Rural y Marino, págs. 77 ss.; C. HoRgué BaEna y F. Jiménez de Cisneros Cid (2010), en El Derecho de costas en España, dir. E. SÁncheZ GoyanEs, La Ley-Wolters Kluwer; F. Sospedra NAVAS (2004), «Los conflictos entre el dominio marítimo terrestre y la propiedad privada», Poder Judicial, págs. 247 ss.; C. Horgué BAENA (1995), El deslinde de las costas, Tecnos, Madrid; J. González SALINAs (2000), Régimen jurídico actual de las costas, Civitas, Madrid, págs. 637 ss.; E. Desdentado Daroca (2007), La expropiación de enclaves privados en el litoral, Civitas, Madrid, págs. 78 ss. 
CE; ya que el artículo 14 permite reaccionar contra el deslinde 2 . La Ley 2/13 no cambia esencialmente el esquema, si bien, tras ella, determinados terrenos dejan de ser demaniales; lo que exigirá nuevos deslindes y el reintegro de los terrenos a sus antiguos titulares ${ }^{3}$.

El RD 876/14 trata de mejorar las relaciones entre el Registro de la Propiedad y el deslinde. Pero pervive el problema fundamental. Como es sabido, el TC entendió que la ampliación del demanio marítimo-terrestre tras la LC constituye una expropiación legislativa, cuyo justiprecio consiste en una concesión. La Ley 2/13 mantiene sustancialmente esta regulación; si bien aclara que la concesión asimismo procede cuando se modifique la línea de deslinde debido a un cambio en la configuración de la costa, y además alarga los plazos y establece la transmisibilidad entre vivos de las concesiones ${ }^{4}$. Aun así, el valor de éstas es siempre inferior al de la propiedad ${ }^{5}$. En todo caso, para el TEDH,

2 A mi juicio, las acciones civiles del artículo 14 de la Ley 22/88 son residuales: si el orden contencioso-administrativo es competente para fiscalizar el deslinde tanto en aspectos formales como de fondo, y si estos deslindes declaran la titularidad demanial del Estado, la anulación del deslinde tendrá eficacia jurídico-real: el terreno volverá a su titularidad anterior, con independencia de que pueda existir después una controversia civil entre particulares por esa titularidad. Puede verse M. ${ }^{a}$ J. Alonso MAS (2013), "¿Son viables las acciones civiles frente al deslinde de las costas?», RAP, 192, págs. 181 ss. Para la STS de 22-1-15, no obstante, las acciones civiles frente al deslinde subsisten plenamente; afirma que el orden contencioso sólo es competente sobre la legalidad extrínseca del deslinde.

3 En algún caso, la Ley 2/13 simplemente ha implicado un cambio en la línea de la ribera del mar, como sucede con los terrenos interiores a los paseos marítimos, conforme a su DA 3. ${ }^{\text {a }}$ Vid. M. ${ }^{a}$ J. Alonso MAS (2014), «Dominio público marítimo terrestre y propiedad privada tras la Ley $2 / 13$ », RCDI, 742, págs. 491 ss.

Sobre la Ley 2/13, M. García PÉrez y F. SAnz LARruga (2014), «Reflexiones en torno a la Ley 2/13, de 29 de mayo, de protección y uso sostenible del litoral y de modificación de la Ley 22/88, de 28-7, de Costas», en La nueva regulación de las costas. Actas del IX Congreso de la Asociación Española de Profesores de Derecho Administrativo, INAP, Madrid, págs. 57 ss.; en el mismo volumen, A. MENÉNDEZ REXACH (2014), «La nueva regulación de las costas: un giro hacia el dominio privado marítimo terrestre», págs. 13 ss.; M. C. NúÑEZ LozANo (2013), La reforma de la Ley de costas de 2013, Tirant lo Blanch, Valencia; B. Lozano Cutanda (2013), «La Ley 2/13, de 29 de mayo, de protección y uso sostenible del litoral: las diez reformas clave de la Ley de Costas», Diario La Ley, 3-6-13; B. Noguera de la Muela y J. Aguirre Font (2013), «Costas y urbanismo: de la Ley de costas al proyecto de Ley de protección y uso sostenible del litoral y de modificación de la Ley 22/88, de costas", en Bienes públicos, urbanismo y medio ambiente, coords. F. LóPEz RAMón y V. Escartí Escudé, Marcial Pons, Madrid, págs. 301 ss.; J. F. Pérez Gálvez (dir.) (2013), Costas y urbanismo. El litoral tras la Ley $2 / 13$, de protección y uso sostenible del litoral y de modificación de la Ley de costas, La Ley, Madrid; F. SANZ LARRUga (2013), «La reforma de la Ley de costas o la apertura de la caja de Pandora», Revista Aranzadi de Derecho Ambiental, 25, págs. 11 ss.; F. Pons Cánovas (2015), El nuevo régimen jurídico de las costas, Aranzadi, Cizur Menor.

4 Vid. Sanz Larruga y García Pérez (2014: 89). Además, esta Ley equipara sustancialmente a los titulares amparados en el artículo 34 LH con aquellos que hubieran obtenido una sentencia firme estimatoria de su acción declarativa de un derecho histórico de propiedad.

5 Así, para la STS de 14-12-09, en caso de rescate anticipado no hay que indemnizar el cien por cien del valor de la concesión, ya que ese valor disminuye conforme se aproxima el momento de la extinción.

Y no es éste el único problema. En efecto, el deslinde no sólo señala la línea del demanio marítimo-terrestre, sino además la de la ribera del mar. Esto tiene importancia a efectos de 
el justiprecio no siempre tiene que ser equivalente al valor real: basta una relación razonable y proporcionada, atendiendo a la importancia de la causa expropiandi; aunque para algún autor, como CiERco SEI$\mathrm{RA}^{6}$, esta jurisprudencia se refiere a casos excepcionales.

Pues bien, la Sala Tercera entiende que los deslindes del demanio marítimo-terrestre pueden modificarse, siguiendo el procedimiento previsto para su aprobación y sin necesidad de revisión de oficio, no sólo cuando se altere la configuración de la costa o se produzca un cambio legislativo; sino siempre que resulte necesario para ajustarlos a la realidad, aunque el desajuste se deba a un error previo de la Administración en la determinación de la línea de deslinde.

Esto plantea problemas tanto en relación con el derecho de propiedad como en relación a la seguridad del tráfico inmobiliario, garantizada por el Registro. En efecto, puede que se apruebe un deslinde, que incluya unos terrenos y excluya otros. Sobre los terrenos excluidos pueden tener lugar operaciones de tráfico inmobiliario, amparadas en el Registro; ya que han quedado fuera del deslinde. El adquirente confiará en que, salvo que cambie la normativa o se produzca una modificación física del litoral, esos terrenos seguirán siendo de dominio privado. Pero puede que, más tarde, se inicie un procedimiento para modificar la línea de deslinde, considerando que la previa era errónea por haber excluido del demanio terrenos merecedores de esa calificación; y finalmente se apruebe un nuevo deslinde que incluya esos terrenos antes excluidos. En estos casos, además de vulnerarse la seguridad del tráfico, se socava la confianza legítima de quienes

la servidumbre de protección, donde los usos urbanísticos — sin perjuicio de lo establecido en la DT 3. ${ }^{\mathrm{a}}$ LC y en la DT $1 .^{\mathrm{a}}$ de la Ley $2 / 13$ - se hallan muy limitados. Así, si se modifica la línea de la ribera del mar, cambiará también la configuración de servidumbre de protección; de modo que terrenos que antes de la modificación del deslinde podían ser edificables de acuerdo con el planeamiento, ya no lo sean después. Esta situación puede merecer compensación en determinados casos. Así lo reconoce la STS de 28-12-12, si bien no en relación con un deslinde, sino con un planeamiento costero que reducía la edificabilidad. Sobre la servidumbre de protección y la DT $1 .^{\text {a }}$ de la Ley $2 / 13$, M. CARLón RuIz (2013), Disciplina urbanística de las costas. Sus peculiaridades en la servidumbre de protección, Civitas, Madrid; así como (2015), «La servidumbre de protección de costas. Un estudio a la luz de la Ley 2/13 y del nuevo Reglamento general de Costas», RAP, 196, págs. 137 ss.

6 C. Cierco SeIRa (2015), «El premio de afección en la expropiación forzosa», REDA, 168, pág. 136. Vid. asimismo G. Doménech Pascual (2012a), «Ni más ni menos. Sobre el principio de indemnidad y sus excepciones», REDA, 156, págs. 63 ss.; J. BARCELONA LLOP (2011), «Privación de la propiedad y expropiación forzosa en el sistema del Convenio europeo de derechos humanos», RAP, 185, pág. 74. La doctrina del TEDH ha cobrado mayor relieve con la LO 7/15, que modifica el artículo 102-2 LJCA al establecer, como motivo de revisión de una sentencia, la existencia de un fallo condenatorio del TEDH en relación con la misma; siempre que la violación, por su naturaleza y gravedad, entrañe efectos que persistan y no puedan cesar de ningún otro modo que no sea mediante esta revisión, sin que la misma pueda perjudicar los derechos adquiridos de buena fe por terceras personas. 
se atuvieron a las inscripciones registrales y al previo deslinde, y actuaron conforme a ello. Aunque el problema ha perdido importancia económica, dada la revalorización de las concesiones con la Ley 2/13, sin embargo persiste: no es lo mismo transmitir al heredero la propiedad que una concesión, por largos que sean sus plazos; en el mercado, tampoco vale igual la propiedad de una vivienda que una concesión sobre ella.

Por supuesto, si los terrenos son demaniales finalmente tendrán que deslindarse como tales; pero es dudoso que pueda hacerse del modo indicado por el TS. Una posible solución sería revisar de oficio el previo deslinde - que incurriría en causa de nulidad parcial de pleno derecho ex artículos 47-1-f) de la Ley 39/15 y 9 LC_- y que, en el mismo acto de declaración de nulidad parcial, se determinaran las indemnizaciones procedentes, conforme al artículo 106-4 de la Ley 39/15. Ello, al menos en cuanto el deslinde parcialmente declarado nulo haya generado una situación de confianza a cuyo amparo se hayan llevado a cabo operaciones de tráfico inmobiliario. Además, y aunque a nivel doctrinal se ha sostenido lo contrario, de la LC y el RC se deduce $a$ sensu contrario que no es viable esa modificación permanente de los deslindes; lo que tiene repercusiones sobre la aplicación del artículo 1 del Protocolo Adicional CEDH.

Abordaré en primer lugar los argumentos que emplea el TS. A continuación, las relaciones entre deslinde y Registro. En tercer lugar, la doctrina del TEDH sobre el derecho de propiedad y la seguridad del tráfico inmobiliario amparada en el Registro; y la incidencia de la confianza legítima. Por último, cuál debería ser el procedimiento de modificación de los deslindes y el requisito de la antijuridicidad del daño para el reconocimiento de indemnizaciones.

El problema no se solventa contraponiendo un interés público y exigencia constitucional, la demanialización de la costa, con el derecho de propiedad; porque al otro lado de la balanza no sólo tenemos éste — de rango constitucional—, sino además la seguridad del tráfico inmobiliario y el buen funcionamiento del Registro, que constituyen intereses públicos de primer orden. 
II. LA POSICIÓN DE LA SALA TERCERA SOBRE LA POSIBILIDAD DE MODIFICACIÓN PERMANENTE DE LOS DESLINDES DEL DOMINIO PÚBLICO MARÍTIMOTERRESTRE

Como he indicado, para el TS los deslindes de la costa pueden modificarse, sin necesidad de revisión de oficio, no sólo si cambia la configuración del litoral o se produce una modificación legislativa que afecta a la determinación del demanio marítimo-terrestre, sino también cuando se constata que el deslinde aprobado no se ajusta a la LC o al RC; tanto si ha incluido indebidamente en el demanio terrenos que carecen de sus características como en el caso contrario.

Así, para el TS, no es precisa la revisión de oficio del deslinde cuando éste se revela erróneo, ya que se exige su permanente adaptación a la realidad física ${ }^{7}$. Entre otras, SSTS de 13 y 27-9, 12-1 y 5-12-12:

«... La Administración no está vinculada por deslindes anteriores, pudiendo "redeslindar" nuevamente los terrenos en orden a comprobar si los deslindes anteriores, que son actos firmes, incluyen la totalidad de los terrenos que deben formar parte del dominio público marítimo terrestre... como dijimos en la STS de 14-7-03 "el procedimiento de deslinde... tiene como finalidad constatar y declarar que un suelo reúne las características físicas relacionadas en los arts. 3, 4 y 5..., sin que ello comporte la imposibilidad de practicar ulteriores deslindes si el llevado a cabo resulta incorrecto, incompleto o inexacto, aunque no haya cambiado la morfología de los terrenos, ya que el dominio público maritimo-terrestre viene configurado por hechos naturales que el deslinde se limita a comprobar, por lo que resulta innecesario usar el procedimiento de revisión de los actos administrativos... pues con el deslinde no se persigue la revisión de actos contrarios al ordenamiento jurídico sino la determinación del dominio público marítimo-terrestre a fin de constatar si efectivamente un terreno reúne o no las características contempladas en los arts. 3, 4 y $5 \mathrm{LC}$, y ello cuantas veces fuese necesario, bien de oficio o a pe-

7 De la misma manera, el TS afirma que el deslinde no queda vinculado por el contenido del informe preceptivo y vinculante emitido en relación con el planeamiento urbanístico. Así, SSTS de 27-9 y 5-12-12, y 11 y 13-11-09. 
tición de cualquier interesado, por lo que no cabe argüir, para impedir el deslinde, la existencia de otro practicado anteriormente $y$, si como al parecer sucedió en este caso, el deslinde... no incluyó algunos suelos que reunían las características físicas contempladas en el apartado b) del art. 3.1. ${ }^{\circ}$ de la vigente LC, no existe obstáculo legal alguno para practicar otro que, comprobando esa realidad, así lo declare...» ${ }^{8}$.

Las de 22-3-12, 13-9-13, 16-10-14 y 13-3-15, entre otras, reiteran esta doctrina ${ }^{9}$. La de 13-12-12 afirma, invocando el antiguo artículo 12.6 de la Ley:

«... Teniendo el deslinde un carácter declarativo y no constitutivo y consistiendo, precisamente, en la operación jurídica por la cual se determina, en atención a las características físicas del terreno, si ha de quedar incluido o no dentro del dominio público utilizando los criterios marcados por la LC, lo relevante será si el nuevo deslinde practicado se ajusta o no a los criterios y requisitos legalmente establecidos».

8 «La existencia de un anterior deslinde no impide la realización de otro posterior, al amparo de la vigente LC... lo que se justifica en no haberse incluido en aquél todos los bienes demaniales definidos como dominio público marítimo-terrestre... En este sentido, en la STS de 15-3-12 — recogiendo lo declarado en la anterior STS de 21-2-06-, indicamos que "Esta Sala del TS ha declarado, entre otras, en sus ss. de fechas 14-7-03, 22-7-03, 29-7-03 y 9-6-04 que, conforme a lo dispuesto en el art. 12.6 de la vigente LC, el procedimiento de deslinde puede incoarse de oficio o a petición de los interesados no sólo cuando por cualquier causa, física o jurídica, se haya alterado la configuración del dominio público marítimoterrestre, sino cuando aparezcan datos o circunstancias de los que se pueda deducir que el deslinde realizado no refleja con exactitud las características físicas de los bienes, ya sea para incluirlos en el dominio público marítimo-terrestre o para excluirlos de él, sin que para ello se precise una previa declaración de lesividad ni acudir al procedimiento de revisión de oficio... ya que el deslinde es un procedimiento especial para revisar de oficio o a instancia de cualquier persona interesada la delimitación del dominio público marítimo-terrestre, y por ello el art. 11 LC establece que "para la determinación del dominio público marítimo-terrestre se practicarán por la Administración del Estado los oportunos deslindes, ateniéndose a las características de los bienes que lo integran...» (STS de 27-9-12).

9 Ésta añade, citando la de 5-12-14: «1. La práctica de un deslinde no vincula ni impide la realización de otro deslinde distinto del mismo tramo de la costa, y no se precisa al efecto indicado promover la declaración de lesividad o la revisión de oficio del deslinde practicado con anterioridad. 2. No cabe oponerse a la práctica de un nuevo deslinde si se alteran los criterios legales delimitadores del deslinde; pero también incluso si no es así; y si, como consecuencia de las actuaciones practicadas, quedara igualmente acreditada la necesidad de ajustar el deslinde a las características físicas de los bienes integrantes de la categoría del dominio público marítimo terrestre. 3. En los supuestos expresados, la realización del nuevo deslinde no constituye el ejercicio de una mera facultad, sino la satisfacción de un deber legalmente establecido». 
La de 22-1-15 insiste en las mismas ideas ${ }^{10}$. La de 5-12-14 niega que el deslinde sea un «acto propio» ${ }^{11}$; luego puede modificarse por otro posterior si resulta incompleto o erróneo, aunque no hayan cambiado las circunstancias.

Pero, además, muchos bienes poseen los caracteres de playa o de zona marítimo-terrestre pero no de modo evidente; ya que para el TS la urbanización de un terreno no le hace perder sin más sus características naturales ${ }^{12}$. Ello es importante a efectos de la seguridad jurídica

10 Esta sentencia resuelve un caso especial. Un Juzgado había declarado propiedad privada algunos terrenos incluidos en un deslinde de 1990. Se obtuvo la ejecución provisional; a resultas de la cual se modificó la línea de deslinde en el sentido indicado por la misma. Pero la Audiencia Provincial consideró que el deslinde estaba sustantivamente bien practicado; por lo que se dio audiencia al interesado y se dictó un acto ratificando la línea de deslinde de 1990. El afectado recurrió, considerando que no se había seguido el procedimiento debido - modificación del deslinde, de acuerdo con su demanda-; pero sus pretensiones se desestimaron porque el deslinde intermedio se había limitado a ejecutar provisionalmente una sentencia luego revocada. La de 9-3-11 resuelve un incidente de ejecución de una sentencia anulatoria de un deslinde por falta de prueba; para el TS, esa anulación judicial no es obstáculo al nuevo deslinde, al no haberse determinado judicialmente la línea correcta del mismo.

11 La de 18-2-14 insiste: «En cuanto a la doctrina de los actos propios cabe citar la STS, Sala $3 .^{\text {a }}$, de 30-9-08 recaída también en un expediente de deslinde, que pone de relieve que la circunstancia histórica del origen de los bienes (se alegaba que la titularidad de los terrenos tuvo su origen en la desamortización y posterior venta por el Estado) no se presenta como un obstáculo jurídico para el desarrollo de la potestad de deslinde de los bienes de dominio público, pues el contenido de dicha potestad... no se ve alterado por el título jurídico, remoto o actual del que traen causa los bienes deslindados, ya que lo determinante en el deslinde no es tal origen jurídico sino la concurrencia de las circunstancias fácticas descritas con precisión en la LC». Y añade que la doctrina de los actos propios «exige y requiere que los mismos se realicen con el fin de crear, modificar o extinguir algún derecho, causando, estando y definiendo la situación jurídica del mismo y debiendo ser concluyente y definitivo» (SSTS, entre otras muchas, de 27-7 y 5-11-87, 15-6-89, 18-1 y 27-7-90, 31-1 y 30-10-95, así como 13-6-00). Pues bien... ello - esto es, la acreditación de la intencionalidad de crear, modificar o extinguir algún derecho- no acontece con el ejercicio que analizamos de la potestad de deslinde...». Una cosa es que en virtud de la CE y la LC no se puedan considerar actos propios obstativos las ventas previas de terrenos desamortizados; y otra que tampoco lo sea el deslinde.

12 La STS de 16-6-04, Civil, afirma, siguiendo la de 9-7-01, que pueden tener carácter demanial terrenos urbanos, si reúnen los caracteres indicados en la LC. Para la de 27-9-12, Tercera: "La circunstancia de que un suelo haya sido incorporado a un proceso urbanizador no desnaturaliza su condición geomorfológica, estando contemplada en las DDTT de la propia LC la compatibilidad del dominio público marítimo-terrestre con la clasificación como urbano del suelo por haber sido urbanizado en ejecución del planeamiento, de manera que la urbanización de un terreno no constituye un hecho excluyente de la definición legal contenida en los arts. 3.1 b LC y 3.1 b RC, por lo que si, como en este caso, se ha demostrado que constituye un importante depósito de arenas litorales, debe incluirse en el dominio público...». Pero si el terreno está urbanizado puede haber perdido sus características naturales. Vid. asimismo las de 12-1 y 23-2-12. La de 19-4-12, Tercera - FJ aceptado de la sentencia recurrida-, indica: «lo que importa en la regulación legal no es el terreno tal como ha sido transformado por obras o instalaciones sino tal como es por naturaleza, de manera que las características naturales son las que determinan su calificación jurídica y las que han de ser tenidas en cuenta al trazar el deslinde»; vid. también STS de 21-6-05, citando los precedentes anteriores siguientes: Ss. de 20-10-03, 30-12-03, 10 y 12-2-04, 2-3-04, 4-5-04, 5-5-04 y 11 5-04. En todo caso, la regulación del RD 876/14 en relación con las dunas, artículos 3 y 4, puede determinar la exclusión del dominio público de muchos terrenos urbanizados sobre ellas. 
y la confianza legítima; ya que muchas veces no será previsible la inclusión en un nuevo deslinde de terrenos excluidos del anterior.

\section{CRÍTICA PRELIMINAR A LOS ARGUMENTOS UTILIZADOS POR EL TS}

\section{Sobre el carácter «declarativo» de los deslindes de costas}

Para el TS, la clave estriba en el carácter «declarativo» del deslinde, que debe limitarse a incluir los terrenos que, conforme a las normas legales, poseen los caracteres del demanio marítimo-terrestre; y excluir los restantes. Pero así se incurre en una imprecisión: no es que el deslinde sea por ello «declarativo», sino que es un acto reglado; aunque su práctica exija aplicar conceptos jurídicos indeterminados ${ }^{13}$. Es decir, los terrenos deben considerarse demaniales siempre que posean esos caracteres; el deslinde se limita a constatar una realidad. La línea de deslinde debe partir de un presupuesto fáctico — la configuración de la costa y características naturales de los terrenos-; y el deslinde constituye la operación técnica para su constatación ${ }^{14}$.

El TS utiliza, sin embargo, la expresión «el deslinde es declarativo»; lo que va más allá. El carácter declarativo significaría en puridad que, aunque el terreno no se incluya en el deslinde por un error técnico, pese a ello es demanio marítimo-terrestre. En suma, el carácter decla-

Critican esta jurisprudencia Alonso Mas (2014: 476) y Desdentado Daroca (2007: 105 ss.). Esta autora entiende que una cosa es que existan algunas obras y edificaciones sin que el terreno haya perdido sus características naturales, como pasa con un edificio aislado en una playa; y otra que esas características se hayan perdido, al existir una urbanización o incluso un pueblo entero sobre antiguas dunas, que además no eran demaniales antes de la Ley 22/88. Así, afirma que si el terreno está degradado y ha perdido antes de la LC sus características, la LC no debería aplicarse retroactivamente. En todo caso, la DA 3. ${ }^{a}$ de la Ley 2/13 muchas veces evitará ese resultado. Además, la interpretación de la autora es más coherente con la posición del TS sobre el artículo 4-5 LC. Conforme a éste, salvo desafectación, los terrenos que hayan perdido sus características naturales de playa, acantilado o zona marítimo-terrestre siguen siendo demaniales; sin embargo, desde la STS de 5-11-10, se exige justificación expresa y suficiente para que los terrenos sigan integrados en el demanio. Para la STJUE Cascina, de 3-4-14, cuando se han perdido irreversiblemente los valores que justificaron la declaración de LIC, el Estado debe promover su desclasificación; máxime si el terreno es de un particular, ya que en tal caso la no desclasificación podría lesionar el derecho de propiedad.

13 Por otra parte, algunos de esos conceptos jurídicos indeterminados no lo son tanto: muchos vienen definidos en la Ley y el RC; con lo que la inicial indeterminación queda sensiblemente aminorada.

14 Como afirma T. R. FERnÁndez Rodríguez (2015), «La discrecionalidad técnica: un viejo fantasma que se desvanece», $R A P, 196$, págs. 211 ss., es un contrasentido hablar de "discrecionalidad técnica»: una operación técnica, por esencia, no puede llevar consigo la relativa libertad de actuación que la discrecionalidad comporta. Puede verse asimismo M. ${ }^{a}$ J. Alonso MAs (1998), La solución justa en las resoluciones administrativas, Tirant lo Blanch, Valencia. 
rativo implicaría que el terreno es demanial aun si no se incluye formalmente en el deslinde; siempre que posea las características indicadas en la LC. Es decir, los terrenos no se convertirían en demaniales con el deslinde, sino que ya lo eran con anterioridad; el deslinde no sería «constitutivo». Posiblemente, ésta sea la clave de bóveda de esta línea jurisprudencial.

Pero esto no tiene en cuenta la eficacia jurídico-real y registral de los deslindes del demanio marítimo-terrestre. Éstos, al igual que los del dominio público hidráulico y de las vías pecuarias, no sólo tienen efectos posesorios, sino declaran la titularidad demanial del Estado ${ }^{15}$. El artículo 13 LC utiliza esta expresión. Pero el deslinde produce importantes modificaciones en la realidad jurídica, al tener eficacia para rectificar los asientos registrales. Así, es dudoso que posea simplemente "eficacia declarativa» ${ }^{16}$. Sólo con el deslinde se constata la concurrencia de las características físicas del demanio marítimo-terrestre en un terreno - SSTS de 2-6-10 y 28-5-08-; por ello, sólo desde ese momento podrá decirse que, efectivamente, el terreno se integra en el dominio público; y ello hace cuestionable la afirmación del carácter «declarativo» del deslinde. Pero la posibilidad, afirmada con reiteración por el TS, de que un deslinde pueda completarse con otro posterior, podría tener sentido si el deslinde tuviera mera eficacia declarativa; lo que resulta cuestionable ${ }^{17}$.

15 La STS de 25-4-07, Civil, transcrita por STS de 22-1-15, Tercera, indica: «el deslinde confiere, además de un título posesorio, un título de dominio sobre los bienes que, por revestir las características naturales del "demanio", tal y como lo entiende el artículo $132 \mathrm{CE}$, quedan incorporados en el dominio público marítimo-terrestre, como se infiere de la lectura de los arts. 13.1 LC de 1988 y 28.1 RC. Es más, junto con esa eficacia declarativa, el deslinde produce efectos registrales pues, una vez aprobado, es título hábil y suficiente para solicitar y obtener la anotación preventiva del dominio público en la inscripción de aquellos bienes incluidos en el demanio, según el deslinde, y permite no sólo la constancia tabular del carácter demanial de tales bienes, sino incluso la rectificación de los asientos contradictorios a dicho carácter y condición, y a la titularidad pública que es inherente a ellos (art. 13.2 LC y 29.1 RC)».

16 Así, F. J. Sospedra NAVAS (2005), "La impugnación jurisdiccional del deslinde de bienes públicos», Revista La Ley, núm. 12, junio 2005, entiende que el deslinde de costas es constitutivo; frente a los regulados en la Ley 33/03, que poseen eficacia declarativa. No obstante, Desdentado Daroca (2007: 81 ss.) concluye que el deslinde de la costa es declarativo; al menos, cuando se limitan a constatar que el terreno posee indubitadamente las características propias del dominio público marítimo-terrestre. Sin embargo, matiza esta idea cuando se trata de bienes del dominio público marítimo-terrestre de tipo artificial; o cuando los límites del bien demanial resultan imprecisos, como pasa con las dunas. En estos casos, entiende defendible que el deslinde sea constitutivo. Vid. asimismo M. DEL P. RodRíGUEz GoNZÁLEZ (1999), El dominio público marítimo terrestre: titularidad y sistemas de protección, Marcial Pons, Madrid, págs. 285 ss. Para Horgué BAEna (1995: 318), el deslinde tiene carácter declarativo, ya que se limita a constatar que los bienes poseen las características propias del dominio público marítimo-terrestre de acuerdo con la norma.

17 También GonZÁleZ-VARAS IBÁÑEZ (1995: 64) entiende que el deslinde de costas es constitutivo y atribuye la titularidad demanial al Estado. Entre los civilistas, para MEco TÉBAR (1998: 65 ss.) el deslinde es declarativo, no constitutivo; afirma que su eficacia estriba en de- 


\section{Contenido y efectos del deslinde de costas}

Durante mucho tiempo, el TS sostuvo que el procedimiento de deslinde de costas no caducaba; al entender que no concluía con un acto de gravamen ${ }^{18}$. Subyacía a ello el argumento antes indicado: el deslinde se limitaría a incluir o excluir unos bienes del demanio marítimoterrestre, bajo la sola consideración de sus características físicas legalmente determinadas.

La Ley 53/02 aclaró, sin embargo, que este procedimiento, si se inicia de oficio, caduca por el transcurso del plazo para resolver y notificar. En efecto, estos deslindes pueden producir efectos desfavorables: terrenos hasta entonces propiedad privada pasan al dominio público. Que un acto administrativo que rectifica inscripciones registrales a favor de particulares y por el que se instrumenta una expropiación no sea un acto de gravamen o no produzca efectos desfavorables es un contrasentido. De hecho, la STS de 26-5-10, como hemos visto, afirma que el expediente iniciado tras la Ley 4/99 y que no se notifica en plazo caduca, ya que puede producir un efecto desfavorable o de gravamen; lo mismo la de 25-3-15.

Que el deslinde produzca un efecto potencialmente de gravamen es claro si atendemos al artículo 12-4-c) LC: incoado el expediente, el Registrador tomará nota marginal que indique que los terrenos quedan a resultas del deslinde en tramitación y que a consecuencia del

marcar los lindes y no en atribuir la titularidad demanial. E. GARCía DE ENTERRÍA (2006), «Inscripción registral y facultades de recuperación posesoria por la Administración», REDA, 129, pág. 132, entendía que el deslinde de la costa es declarativo, dado el carácter natural de estos espacios demaniales; por lo que también consideraba justificada la regulación del artículo 13 LC.

De hecho, si hasta la STS de 26-5-10 se afirmaba que no caducaban los expedientes iniciados antes de la Ley 53/02 porque no se producía un efecto limitativo de derechos, sino la mera declaración de que la finca reúne los caracteres físicos indicados en la LC — STS de 3012-03, entre otras-, desde esa sentencia se entiende que los incoados tras la Ley 4/99 sí caducan, por tener efectos desfavorables.

18 Nos lo recuerda la SAN de 31-5-10, entre otras, confirmada por STS de 18-2-14: «La reciente STS, Sala 3. a, de 18-2-09, recaída en un supuesto similar al presente, señala: "con anterioridad a la Ley 53/02 ... la interpretación del ordenamiento jurídico relativo al demanio marítimo-terrestre y a la caducidad de los procedimientos administrativos de deslinde era la sostenida por la jurisprudencia de esta Sala Tercera del TS, recogida, entre otras, en nuestras Sentencias de fechas 2-6-04, 19-7-05, 20-7-05, 27-7-05, 28-7-05 y 4-1-07...

En las aludidas Sentencias, esta Sala declaró que ni la Ley ni el RC (con anterioridad a la aludida adición introducida en el artículo 12.1 por la Ley 53/02) tenían establecido un plazo máximo para dictar resolución, sin que pueda aplicarse el supletorio de tres meses, que establecía el artículo 42.2 de la referida Ley 30/92, cuando los procedimientos fueron iniciados de oficio y no a solicitud de los interesados, sin que, además, pueda calificarse este procedimiento de limitador o restrictivo de derechos, pues el deslinde tiene como finalidad la protección del interés general en declarar o constatar el dominio público marítimo terrestre definido por la Ley... ». 
mismo podrán incluirse en el demanio; el artículo 21-2 RC añade que Costas puede instar anotación preventiva si se trata de fincas no inscritas. Pero ello implica, a sensu contrario, la generación de una legítima expectativa de que los terrenos no incluidos en el deslinde carecen de los caracteres del demanio; lo que es de especial importancia en el caso del tercer adquirente amparado en la fe pública registral. Para las SSTS de 3012-03, 12-11, 31-12-04, 20-7-05 y 23-10-09, el deslinde puede también producir un efecto favorable a los ciudadanos; lo que conectan con la seguridad jurídica. La de 31-12-03 dice lo mismo, y recoge el fundamento de la Sala de instancia relativo a que el deslinde produce efectos favorables en cuanto excluye determinados bienes; si bien, pese a ello, afirma el TS que cabe sin problema la modificación del previo deslinde.

Es decir, a sensu contrario, si un deslinde excluye del demanio unos terrenos, produce una apariencia jurídica favorable para su titular. Además, si los terrenos se habían incluido en un deslinde anterior y el nuevo los excluye, se altera la situación de los terrenos en beneficio del antiguo titular; pensemos que aquéllos se hubieran incluido por error en el deslinde previo. Pero si ese segundo deslinde produce efectos favorables en el titular de los bienes, ¿no será precisa la revisión de oficio para eliminar esos efectos, con carácter previo al tercer deslinde que los incluya? ${ }^{19}$.

Dejando aparte este supuesto, desde el momento en que el deslinde deja fuera unos bienes por entender que no poseen los caracteres del demanio marítimo-terrestre, produce la legítima expectativa de que los bienes no son demaniales; aunque formalmente no altere el status inicial respecto de su titularidad. Aunque el acuerdo de incoación no hubiera incluido esos terrenos, se deslinda un determinado tramo de costa; luego, practicado el deslinde, ese tramo queda ya deslindado, y se supone que lo que queda fuera del deslinde no debe incluirse en el mismo $^{20}$.

Es decir, si el deslinde posee eficacia constitutiva respecto de los terrenos que incluye como demaniales, al menos declara que no lo son los excluidos. Si puede considerarse el deslinde como acto declarativo en

19 Tema distinto es la revisión de oficio de un deslinde a solicitud del interesado afectado negativamente por el mismo. Puede verse STS de 25-3-15.

20 Ello, con independencia de que la previsión de la Ley 2/13 conforme a la cual los terrenos interiores a los paseos marítimos construidos o autorizados por el Estado en el período que media entre la entrada en vigor de la Ley 22/88 y la Ley 2/13, quedan excluidos de la ribera del mar, implicará un importante coto a esta jurisprudencia. En efecto, dichos terrenos, por mucho que se hallen configurados en el subsuelo por arena o dunas, ya no pueden ser deslindados como ribera del mar; lo hubieran sido o no con anterioridad. Vid. Alonso Mas (2014: 491 ss.) 
algún aspecto, lo es en relación con los terrenos excluidos ${ }^{21}$. Pero esto no significa que dicho acto pueda ser desconocido sin más por la Administración ${ }^{22}$. El deslinde, al dejar fuera un terreno, puede producir situaciones amparadas por la confianza legítima.

Por supuesto, si los terrenos excluidos del deslinde poseen las características propias del demanio marítimo-terrestre, finalmente deberán incluirse en el mismo mediante un deslinde posterior. Pero ello no implica que pueda desconocerse sin más la situación de confianza generada por el deslinde previo que excluyó los terrenos. Afirmar que no se infringe la confianza protegible porque el deslinde puede completarse con otro posterior incurre en una petición de principio; además, así se desconoce que una actuación conforme a Derecho en su contenido puede vulnerar la legítima confianza. El TS señala que la infracción de la legítima confianza, si el acto es reglado y manifestación de una potestad de ejercicio debido, no anulará el acto; pero sí dará lugar a indemnización ${ }^{23}$. En nuestro caso, aunque por hipótesis se sostenga la posibilidad de modificar un deslinde para incluir terrenos en principio excluidos, eso no significa que la confianza legítima no se lesione: hay una actuación previa de los poderes públicos, derivada de un acto que pone fin a un procedimiento, de la que se deduce la apariencia de que los terrenos no son demaniales; lo que puede dar lugar a inversiones y operaciones de tráfico inmobiliario. No puede mantenerse una espada de Damocles que amenace permanentemente la seguridad del tráfico inmobiliario, negando además el derecho a indemnización, partiendo de que el deslinde nunca es definitivo; ya que ello implica sacrificar de modo absoluto la seguridad jurídica y la confianza legítima, por cuanto el carácter demanial de un terreno normalmente no es eviden-

21 En todo caso, la posición del TS es la contraria. Así, STS de 18-12-13: «esto ni viola la seguridad jurídica del artículo 9.3 CE (porque este principio no puede asegurar la inmutabilidad de los deslindes) ni infringe el art. 106 de la LRJPA, que regula la revisión de oficio de los actos administrativos (porque un deslinde administrativo declara que ciertos bienes son de dominio público, pero no es un acto declarativo de derechos para los propietarios de las fincas colindantes, en el sentido de que declare formalmente que esas fincas no son dominio público)».

22 Las licencias urbanísticas, por ejemplo, durante mucho tiempo se han considerado actos declarativos; pero para su eliminación o bien hay que acudir a la revisión de oficio o al procedimiento de lesividad, o bien a su revocación con indemnización en caso de cambio de planeamiento.

23 Afirma la SAN de 30-3-15: "declara la STS de 10-9-12, y reitera la STS de 30-10-12, "la plena satisfacción de la pretensión desatendida no puede obtenerse en aquellos supuestos en los que está excluido el ejercicio de la potestad discrecional de la Administración y sometida su decisión al cumplimiento de determinados requisitos legales, cuya carencia ha de impedir acceder a lo solicitado. En estos supuestos el quebrantamiento del principio de confianza legítima tan solo podrá llevar consigo la posibilidad de ejercitar una acción de responsabilidad patrimonial por los perjuicios ocasionados al administrado como consecuencia del mismo». 
te a simple vista. No debe confundirse la necesaria inclusión de determinado terreno en el demanio con la ausencia del deber de indemnizar.

\section{La doctrina de los actos propios}

El TS considera que ni es acto propio la enajenación de los terrenos por el Estado al amparo de la legislación desamortizadora; ni los informes preceptivos y vinculantes del artículo 117 LC —STS de 18-1213, por ejemplo-; y ni tan siquiera el acto de deslinde. Sin embargo, este último sí posee los caracteres de los actos propios.

En efecto, la STS de 15-12-05 señala, invocando la de 13-6-00 (Civil):

«No resulta aplicable al caso la doctrina de los actos propios, que exige y requiere que los mismos se realicen con el fin de crear, modificar o extinguir algún derecho, causando, estando y definiendo la situación jurídica del mismo y debiendo ser concluyente y definitivo - ss., entre otras muchas, de 27-7 y 5-11-87, 15-6-89, 18-1 y 27-790, 31-1 y 30-10-95-», pues «no pueden reputarse como actos propios los que no dan lugar a derechos y obligaciones - ss. de 9-2-62, 16-6 y 5-10-84, 23-6, 25-9 y 5-10-87, 25-1 y 4 y 10-5-89, 20-2-90 y 10-6-94, entre otras...- y requiere que los hechos tengan una significación y eficacia jurídica contraria a la acción ejercida — sentencia de 6-4-62 - lo que aquí no ocurre, precisando tener eficacia jurídica bastante a producir una situación de derecho contraria a la sostenida por quien lo realice - - ss. de $4-7-62,5-3,14-5$ y $27-11-91,9-10-93$ y $17-12-94-»$, ya que «han de tratarse de actos que por su trascendencia o por crear convención causen estado, no pudiendo ser alterada unilateralmente la relación jurídica por ellos creada y han de ser hechos de inequívoca significación - ss. de 7-10-32, 27-11 y 20-12-52, 30-1-63 y numerosas posteriores—». «En definitiva — concluye la STS—, el acto propio contra el que no puede ir válidamente aquel que lo realiza es el llevado a efecto con ánimo de producir una consecuencia jurídica, pero han de ser "los trascendentales" de los que no cabe regresar contradiciéndose por vincular a quien los realiza a un estado o situación ju- 
rídica que por su proyección más allá del ámbito unilateral es inalterable — ss. de 11-10-66 y 12-4-93-».

La STS (también Sala 1. ${ }^{\text {) }}$ ) de 21-12-01 añade que «viene a ser del todo necesario que el acto se presente como solemne, preciso, claro, determinante y perfectamente delimitado, no ambiguo ni inconcreto - ss. de 22-9 y 10 10-88 y 4-6-92-».

Por otra parte, esta Sala —STS 4-6-92 - ha exigido que «los denominados actos propios vinculantes causen estado definiendo inalterablemente la situación jurídica de su autor, o que vayan encaminados a crear, modificar o extinguir algún derecho opuesto a sí mismo (ss., entre otras, de 22-6 y 5-10-87, 15-6-89, 18-1 y 22-7-90). Además, el acto ha de ser solemne, expreso, no ambiguo y perfectamente delimitado, definiendo de forma inequívoca la situación del que lo realiza (STS de 22-9 y 10-10-88)».

Algunas de estas afirmaciones son redundantes; por ejemplo, que la relación jurídica creada por el acto no pueda alterarse unilateralmente es consecuencia del acto propio; más que una nota que lo defina. Que el acto sea concluyente, determinante y no ambiguo depende de su contenido; pero la demarcación de la línea de deslinde no debe adolecer de ambigüedad. Por lo demás, el deslinde es un acto definitivo; no de trámite.

El problema podría plantearse en relación con la exigencia, afirmada por esta sentencia, de que el acto propio cree, modifique o extinga derechos o situaciones jurídicas; ya que el deslinde altera la situación de los terrenos que se incluyen, pero normalmente no la de los colindantes. Sin embargo, no sólo se consideran por el TS actos propios los que crean, modifican o extinguen situaciones jurídicas, sino también los que definan inalterablemente una situación ${ }^{24}$. Es decir, también pueden ser actos propios los que se limitan a constatar una situación jurídica ${ }^{25}$.

De hecho, para la STS de 28-12-12, la doctrina de los actos propios se liga a los principios de buena fe y protección de la confianza; ello es

24 Para GonZÁlez-VARAs IbáÑEZ (1995: 27), el deslinde de costas es constitutivo y no provisional. Para J. R. CALERo Rodríguez (1995), Régimen jurídico de las costas españolas, Aranzadi, Pamplona, págs. 396 ss., al deslinde no le es aplicable la doctrina del acto propio porque ello implicaría cristalizar las dependencias demaniales; pero parece referirse a que el previo deslinde no es oponible a los cambios normativos.

25 Pensemos en la inscripción del nacimiento en el Registro Civil; obviamente, esa inscripción ni crea la persona físicamente, ni le otorga la personalidad, pero nadie duda que dicha inscripción reúne los caracteres de un acto propio. 
importante porque, como hemos visto, la exclusión de unos terrenos del deslinde genera la apariencia jurídica de que no forman parte del demanio $^{26}$.

Es cierto que esta sentencia añade que la doctrina de los actos propios no puede amparar situaciones contrarias al Ordenamiento. Sin embargo, ambas se refieren a casos distintos al que nos ocupa. En el resuelto por la de 15-12-05, lo invocado como acto propio era una licencia previa aducida como obstáculo a la aprobación de un plan general. El TS reconoce que la licencia era un acto propio; pero no impedía la aprobación del plan que modificaba el régimen del terreno. En la segunda, el invocado como acto propio no era tal: justamente, afirmaba que el cambio en el planeamiento impedía aplicar la normativa anterior; es más, finalmente se reconoció una indemnización. Es decir, en ambos casos se trataba de la modificación de una situación jurídica previa mediante la potestad de planificación; lo que nada tiene que ver con la modificación de un acto administrativo en perjuicio del afectado por otro posterior de igual índole ${ }^{27}$. Además, no se trata de que el acto propio ilegal se deba mantener, sino que para eliminarlo habrá de seguirse el cauce procedimental adecuado y en su caso indemnizar.

En resumen: el deslinde de costas es un acto definitivo; y la doctrina de los actos propios, si bien no puede justificar la pervivencia de situaciones contrarias a Derecho, sí exige que dichas situaciones sean eliminadas por el cauce procedimental adecuado.

26 «Tal doctrina, surgida originariamente en el ámbito del derecho privado, significa la vinculación del autor de una declaración de voluntad al sentido objetivo de la misma y la imposibilidad de adoptar después un comportamiento contradictorio, estando la misma doctrina estrechamente ligada al principio de buena fe y de protección de la confianza legítima, positivizados en el articulo 3.1 LRJPA, y que ha sido acogido igualmente por la jurisprudencia del TS (SSTS de 1-2-90; 13-2 y 4-6-92; 28-7-97, así como, de la Sala Primera SSTS de 13 6-00 y 21-12-01, todas las en ellas citas); en consecuencia tal doctrina supone que la actuación de las Administraciones Públicas no puede ser alterada arbitrariamente.

En concreto, en la STS de esta Sala de 26-2-01, dijimos que "Tanto la doctrina del TC como la Jurisprudencia de este Alto Tribunal (STS de 1-2-99) considera que el principio de buena fe protege la confianza que fundadamente se puede haber depositado en el comportamiento ajeno e impone el deber de coherencia en el comportamiento propio. Lo que es tanto como decir que dicho principio implica la exigencia de un deber de comportamiento que consiste en la necesidad de observar de cara al futuro la conducta que los actos anteriores hacían prever y aceptar las consecuencias vinculantes que se desprenden de los propios actos, constituyendo un supuesto de lesión a la confianza legítima de las partes "venire contra factum propium"».

27 Y en la de 23-11-11, relativa al deslinde de una vía pecuaria, tampoco se aceptó la existencia de un acto propio - previas expropiaciones de los terrenos luego deslindados- porque al tiempo de la expropiación era el Estado y no la Comunidad Autónoma el titular de la vía pecuaria; aunque se añade como refuerzo que la expropiación se llevó a cabo con los titulares registrales y en aquel momento las vías pecuarias no constaban en el Registro. 


\section{La discutible base legal de la «complementación» de los deslindes que adolecen de errores técnicos}

Los argumentos anteriores serían suficientes para rebatir la posición del TS, que considera viable la modificación de los deslindes; tanto para excluir terrenos del dominio público como para incluir otros. Pues bien, lo anterior se refuerza si se tienen en cuenta los datos normativos ofrecidos por la LC y el RC ${ }^{28}$. De ambos se deduce que no es viable modificar un deslinde si no se han alterado las circunstancias fácticas ni las normas aplicables ${ }^{29}$. Además, como veremos, la doctrina del TS no se adecúa a los principios de seguridad jurídica y confianza legítima. El punto de partida estriba en que a través del deslinde de costas se materializa una expropiación, donde además la indemnización no equivale al valor de lo expropiado.

En efecto, a mi juicio, de la LC se desprende que los deslindes del demanio marítimo-terrestre sólo pueden modificarse ante cambios en la realidad física o modificaciones normativas. Esta idea subyacía al derogado artículo 12-6, tan invocado por el TS ${ }^{30}$; y se reitera en la Ley 2/13. El artículo 13 bis-1 LC, añadido por ésta, señala que los deslindes se revisarán cuando se altere la configuración del demanio; asimismo, artículo 27-1 RC, que concreta en qué casos podemos revisar el deslinde ${ }^{31}$.

28 Vid. Menéndez Rexach (2014: 40); para quien la Ley 2/13 debería haber sido más explícita en cuanto a los bienes inscribibles, ya que remite a la LPAP y ésta alude a los bienes demaniales susceptibles de inscripción, artículo 36. Vid. también GARCía PÉREz y SANZ LARRUGA (2014: 85 ss.).

29 En cualquier caso, no es ésta la única interpretación posible. Así, para HorguÉ BAENA, «El deslinde administrativo de los bienes del dominio público marítimo-terrestre y de los bienes colindantes", en El Derecho de costas en España (2010: 405), cuando se produce un cambio normativo o en la configuración de la costa, es obligatorio proceder al deslinde o a su modificación; pero, partiendo de que el deslinde posee carácter declarativo, añade (2010: 420) que la Administración no queda vinculada por el deslinde previo. No obstante, si el deslinde pretende adecuar la realidad física a lo determinado en las normas, siempre que se produzca un desajuste el mismo debería ser obligatorio; y no sólo en los casos apuntados.

30 El precepto indicaba: «Cuando por cualquier causa se altere la configuración del dominio público marítimo-terrestre, se incoará expediente de deslinde o de modificación del existente, con los efectos previstos en los apartados anteriores». A sensu contrario, no permitía modificar el deslinde sin dicho cambio en la configuración del dominio público marítimoterrestre.

31 «a) Los deslindes de zona marítimo-terrestre vigentes se revisarán en caso de que, aplicando los criterios indicados en el art. 4.a) de este reglamento, con datos obtenidos a partir de la entrada en vigor del presente reglamento, la línea de la zona marítimo-terrestre resultante quede ubicada tierra adentro de la vigente, pasando los terrenos inundados a formar parte del dominio público marítimo-terrestre. b) Igualmente se revisarán los deslindes de zona marítimo-terrestre vigentes, desplazando dicho límite hacia el mar, si se demuestra que un temporal, con período de retorno de 50 años, no alcanza el límite fijado en dicho deslinde Para dicho cálculo no se tendrán en cuenta las obras que hayan podido realizarse para disminuir 
Esto supone que, cuando se altere la realidad física, imperativamente ha de practicarse el deslinde; pero también que sólo en este caso, o en el de modificaciones normativas que afecten a la determinación del demanio marítimo-terrestre, podrá revisarse el deslinde previo. La ley no permite activar la potestad de deslinde bajo otra circunstancia. Las potestades administrativas con efecto de gravamen, como el deslinde de costas, sólo pueden ejercitarse cuando una norma legal habilitante lo permita; en este caso, la norma habilitante es clara en cuanto al presupuesto que legitima el ejercicio de la potestad de deslinde.

El artículo 13 bis-1 se complementa con la DT 1-3 y la 1-4. Ésta ordena la práctica del deslinde de los tramos de costa no deslindados conforme a la Ley 28/69 o donde el deslinde estuviera incompleto de acuerdo con ella; esto es, donde no hubiera incluido la totalidad de los terrenos demaniales conforme a su artículo 1 - por ejemplo, por haber reconocido la Administración enclaves históricos de propiedad priva$\mathrm{da}^{32}$ - . Y la DT 1-4 alude a los casos en que el deslinde estuviera completo conforme a la Ley 28/69; pero hubiera que practicar otro para adaptarlo a la Ley 22/88. Asimismo, diversas previsiones de la Ley 2/13 exigen revisar los deslindes para adaptarlos a ella.

En suma, la LC sólo habilita el ejercicio de la potestad de deslinde en ciertas circunstancias: modificación física del litoral; cambio normativo; o los casos de la DT 1-3 — que incluye la ausencia de deslinde-. De hecho, la STS de 14-7-03, en que se basan las demás, aunque argumenta en abstracto la posibilidad de modificación permanente del deslinde, sin embargo se refería a un caso en que el deslinde previo, luego complementado con otro, era anterior a la Ley 22/88; así que ese deslinde sí tenía apoyo en la DT $1{ }^{a 33}$. Y la de 18-12-13 afirma acertadamente:

el alcance del oleaje. c) En los supuestos de incorporación de terrenos previstos en los apartados 7 y 8 del art. 5 de este reglamento y en los de desafectación recogidos en el art. 38 de este reglamento, no será necesario tramitar un nuevo deslinde, sino que será suficiente con rectificar el deslinde existente con información pública y solicitud de informes al Ayuntamiento y la comunidad autónoma, de forma que se adapte la línea definitoria del dominio público marítimo-terrestre al resultado de tales mutaciones demaniales».

32 Vid. Desdentado Daroca (2007: 72).

33 Tras afirmar que estamos ante un acto declarativo y de mera constatación de que concurren ciertas características en los terrenos deslindados, añade que por ello el deslinde puede rectificarse cuando sea incompleto, incorrecto o inexacto, aunque no haya cambiado físicamente la costa; así que la revisión de oficio es innecesaria "pues con el deslinde no se persigue la revisión de actos contrarios al ordenamiento jurídico sino la determinación del dominio público marítimo-terrestre a fin de constatar si efectivamente un terreno reúne o no las características contempladas en los arts. 3, 4 y 5 LC, y ello cuantas veces fuese necesario, bien de oficio o a petición de cualquier interesado, por lo que no cabe argüir, para impedir el deslinde, la existencia de otro practicado anteriormente $y$, si, como al parecer sucedió en este caso, el deslinde aprobado por OM de 5-11-74 no incluyó algunos suelos que reunían las ca- 
«En la STS de 18-2-04, entre otras muchas, hemos expuesto que "aunque no hayan cambiado las características de los bienes puede ser necesaria la práctica de un nuevo deslinde si cambia la normativa aplicable, como es el caso, ya que la LC 22/88 varía la definición y número de estas pertenencias de dominio público marítimo terrestre. $Y$ así viene a prescribirlo la DT 1-4, LC, al hablar de "practicar un nuevo deslinde para adecuarlo a las características establecidas en aquélla para los distintos bienes"...».

Lo dicho se refuerza si se considera que la LC exige aplicar la concesión compensatoria en los casos de la DT $1 .^{\mathrm{a}}$ - cambios normativos- pero también, de forma explícita, a partir de la Ley 2/13, cuando un cambio físico en la costa exija aprobar un deslinde. Es decir, justamente refiere la concesión compensatoria a los dos casos en que se prevé la práctica del deslinde ${ }^{34}$.

En suma: de la LC se infiere que el presupuesto que legitima el ejercicio de la potestad de deslinde es: la ausencia de previo deslinde; o cambios normativos; o la modificación física de la costa. De ningún modo se deduce de ella que un deslinde pueda tener por objeto complementar otro anterior técnicamente equivocado ${ }^{35}$.

Lo anterior no sólo pone de relieve la discutible adecuación de la doctrina del TS a la normativa aplicable: si es así, en estos casos la

racterísticas físicas contempladas en el apartado b) del art. $3.1 .^{\circ}$ de la vigente $L C$, no existe obstáculo legal alguno para practicar otro que, comprobando esa realidad, así lo declare, con lo que ni la Administración del Estado ni la Sala de instancia, al confirmar la decisión de aquélla, han conculcado lo establecido en los arts. 3.1 y 12.6 LC...». Aunque la sentencia realiza afirmaciones abstractas y generales, el supuesto era incardinable en la DT 1-4 LC.

En otra de la misma fecha y dictada en el mismo sentido no se indica la fecha del deslinde previo; pero se supone que asimismo era anterior a la LC, ya que el contencioso frente al primer deslinde data de 1991. En la tercera de esa fecha, el deslinde previo era anterior a la LC, ya que se invocaba por la Administración la DT 1-3.

34 Ya antes de la Ley 2/13, Sospedra NAVAs (2004: 277 ss.) entendía en tal supuesto aplicable la DT 1-4 LC —vid. también GonzÁLEz SALINAS (2000: 287 ss.)—. Pese a ello, afirmaba que en este caso, al preexistir un pleno derecho de dominio, la concesión puede ser insuficiente. Para J. Leguina Villa y E. Desdentado Daroca (2005), «El régimen jurídico de los terrenos ganados al mar y la preservación del demanio costero», RAP, 167, págs. 30 ss., no procedería en tal caso indemnizar porque la privación de la propiedad se debe a causas naturales, salvo si las nuevas características no hubieran determinado la demanialidad conforme a la Ley 28/69 y sí conforme a la LC; en cuyo supuesto afirman que se trata de una expropiación normativa, compensable conforme a la DT 1-4.

35 Preceptos tan genéricos como el artículo 11-1 LC y el 14-1 RC no pueden amparar dicha conclusión. El primero indica: «Para la determinación del dominio público marítimo-terrestre se practicarán por la Administración del Estado los oportunos deslindes, ateniéndose a las características de los bienes que lo integran conforme a lo dispuesto en los arts. 3, 4 y 5 de la presente Ley». Para que una previsión tan genérica permitiera revisar cualquier deslinde para complementarlo, se debería haber establecido expresamente; considerando la eficacia jurídico-real de esos deslindes. 
conversión de la propiedad en concesión constituirá una expropiación ilegal al no haberse seguido el procedimiento debido; y en caso de expropiación ilegal, el TEDH exige indemnización integral y no sólo proporcionada. Otra cosa sería que se modificara la LC para permitir la revisión del deslinde en caso de error técnico; pero en tal caso debería establecerse la indemnización adicional por lesión de la confianza legítima, cuando proceda, en el acto mismo de modificación del deslinde. Después volveré sobre ello; en cualquier caso, el tema no está cerrado ni siquiera a nivel doctrinal, como veíamos.

5. El procedimiento de revisión del previo deslinde que resulta incompleto como consecuencia de un error técnico de la Administración

Frente a todo lo anterior, no se puede argumentar que el deslinde no sirve para anular actos administrativos contrarios al Ordenamiento. Por supuesto, ésta no es la finalidad del deslinde. Pero, precisamente, el Ordenamiento configura procedimientos especiales para la eliminación de actos administrativos ilegales, entre los que no se encuentra el procedimiento de deslinde.

Así, hay que plantear si es precisa la revisión de oficio. No se puede argumentar frente a ello que el deslinde sea - como cualquier potestad administrativa - un poder-deber, o que constituya un acto reglado; porque precisamente la revisión de oficio - o el procedimiento de lesividad, en su caso- sirve para eliminar las manifestaciones antijurídicas del ejercicio de las distintas potestades administrativas. Y, por supuesto, estos procedimientos de revisión sirven tanto frente a actos con elementos discrecionales como ante actos completamente reglados.

Lo que quiere decir el TS es que si el deslinde es ilegal por defecto - por no haber incluido terrenos que poseen las características físicas propias del demanio marítimo-terrestre-, como es obligada su inclusión, el nuevo deslinde no haría sino completar el anterior; y como además esa inclusión resulta obligada, sería inútil la revisión de oficio. El TS considera que el deslinde, que es un procedimiento técnico en el que intervienen los afectados, posee suficientes garantías. Quizá incluso entienda que en el procedimiento de revisión de oficio puede ser difícil articular los requisitos técnicos del deslinde.

No obstante, estas consideraciones son insuficientes. En cuanto a la articulación técnica de los procedimientos, mediante la revisión de oficio se declararía la nulidad parcial del previo deslinde en cuanto no 
incluyó esos terrenos hasta entonces propiedad privada; y esa declaración serviría de presupuesto legitimador del deslinde posterior. Y el hecho de que sea un poder-deber practicar el deslinde y además un acto reglado, en el sentido de que es obligatoria la inclusión de todos los terrenos con determinadas características, no obsta a la necesidad de revisión de oficio: También es un deber de la Administración no dictar actos ilegales; $y$, sin embargo, si dicta un acto ilegal pero favorable al interesado, no puede sin más revocarlo, sino debe acudir a la revisión de oficio o a la declaración de lesividad.

En suma, no puede decirse que como el deslinde debió haber comprendido más terrenos de los que incluyó inicialmente, el mismo pueda «complementarse» mediante otro posterior; porque este nuevo deslinde, más que completar el anterior, lo modifica. La consideración de que el previo «deslinde» complementa el anterior se basa implícitamente en que ese anterior deslinde que ha dejado fuera determinados terrenos, no altera su status quo. Pero, como hemos visto, puede que, con anterioridad al deslinde que deja fuera unos terrenos, se hubiera practicado otro que los hubiera incluido; y en ese caso, el segundo deslinde, que los excluye, modifica el status de dichos terrenos. Y, además, aunque no suceda así, lo que se deslinda es un tramo de costa; y el deslinde, como reconoce el TS, debe comprender todos los bienes que poseen las características propias del demanio marítimo-terrestre. Luego, cuando el deslinde no incluye determinados bienes, lo que está diciendo positivamente es que los mismos no pertenecen al dominio público marítimo-terrestre, sino que son de propiedad privada; y esta afirmación, aunque no responda a la realidad, genera una situación de confianza protegible.

Por ello, a menos que varie la configuración del tramo de costa o se produzca un cambio normativo, la potestad de deslinde de ese concreto tramo se agota en sí misma, sin que quepa volver sobre un deslinde ya practicado para incluir nuevos bienes. Esto es lo coherente con la eficacia registral y jurídico-real de estos deslindes, que comporta que un terreno no puede considerarse demanial salvo que se incluya en un deslinde; como hemos visto.

Si un deslinde es incompleto por no haber incluido todos los terrenos demaniales, no estamos ante errores materiales rectificables conforme al artículo 109-2 de la Ley 39/15. El error material, como indica SOCíAS CAMACHO ${ }^{36}$, puede rectificarse sin que padezca el contenido del

36 J. M. Socías CAMAcho (2002), «Error material, error de hecho y error de derecho. Concepto y mecanismos de corrección», RAP, 157, págs. 157 ss. 
acto; el error de hecho, que sí afecta a ese contenido y causa, si es determinante, su ilegalidad, no puede rectificarse - pese a la confusión que late en el precepto citado-, sino que, en su caso, comportará la anulación del acto mediante el recurso extraordinario de revisión, artículo 125 de la Ley 39/15; o bien permitirá la revisión de oficio o la declaración de lesividad según los casos.

Es verdad que, dada la imprescriptibilidad del demanio, difícilmente podría invocarse el artículo 110 de la Ley 39/15; por lo que la conclusión a la que podría llegarse es que el procedimiento de revisión de oficio no resulta útil. En tal sentido, GonZÁlez SALINAS ${ }^{37}$ señala que poco o nada añadiría el dictamen del Consejo de Estado, ya que estamos ante una función puramente técnica; así que el deslinde podrá modificarse si no se ajusta a la realidad física y a la definición del demanio marítimo-terrestre. Pero el autor introduce un matiz: como se ha producido un error técnico en el deslinde previo - o un error en la interpretación de la norma; o un cambio en esa interpretación-, existirá responsabilidad patrimonial. Como hemos visto, es difícil afirmar que la LC permita modificar el deslinde en estos casos; pero, aunque se entienda de otro modo, la inclusión de un terreno en un deslinde cuando había sido excluido del anterior, sin haber mediado cambio normativo o físico, puede lesionar la confianza legítima y, en tal medida, existirá responsabilidad patrimonial. Así, el Consejo de Estado puede tener un importante papel en la determinación de la procedencia y cuantía de las indemnizaciones.

Otra cosa sería, como veíamos, que se modificara la LC para permitir expresamente la revisión del deslinde incurso en error técnico; en tal caso la revisión de oficio no sería necesaria, pero habría que articular la previsión de la indemnización por lesión de la confianza legítima al tiempo de modificarse el deslinde para evitar deferir a los afectados a un ulterior procedimiento de responsabilidad patrimonial de resultado incierto. Si consideráramos por hipótesis que el artículo 11-1 LC habilita la modificación del deslinde incurso en error técnico, tendríamos que sostener también la exigencia de determinación simultánea de la indemnización. Más adelante volveré sobre ello.

37 (2000: 610 ss.). 


\section{LAS RELACIONES ENTRE DESLINDE Y REGISTRO DE LA PROPIEDAD EN LA NUEVA NORMATIVA DE COSTAS}

La LC intenta armonizar lo dispuesto en su artículo 13 con la protección registral ${ }^{38}$. Para ello, obliga a practicar nota marginal una vez incoado expediente de deslinde ${ }^{39}$. Pero, además, el artículo $15-\mathrm{cu}-$ yas reglas extiende el artículo 16 para los excesos de cabida-, para inmatricular de terrenos de la zona de servidumbre de protección colindantes con la ribera del mar, exige certificación administrativa que indique que los terrenos no forman parte del demanio marítimoterrestre $^{40}$.

En segundo lugar, el artículo 15-4 indica que, si no estuviese aprobado el deslinde, se iniciará el procedimiento en el plazo máximo de tres meses, quedando entretanto la inscripción solicitada en suspenso ${ }^{41}$.

38 Ello es significativo; en otro contexto, I. Revuelta Pérez (2012), «La ponderación del derecho de propiedad en la ejecución de sentencias urbanísticas», en Liber Amicorum Tomás Ramón Fernández, Civitas-Thomson, Madrid.

39 El artículo 21-2 RC indica que el plano del área afectada deberá constar debidamente georreferenciado, con identificación de las parcelas, acompañándose de la documentación catastral a fin de que el Registrador, al expedir la certificación, verifique la correspondencia de esa relación de propietarios con el contenido de los asientos o ponga de manifiesto las discrepancias. Y su artículo 23 solventa el problema de la aparición de fincas no incluidas inicialmente en la certificación de dominio y cargas pero que pudieran asimismo ser afectadas por el deslinde.

40 El artículo 15-2 añade: «Si en la descripción de la finca se expresa que no linda con el dominio público marítimo-terrestre o no se hace declaración alguna a este respecto, el Registrador requerirá al interesado para que identifique y localice la finca en el plano proporcionado al efecto por la Administración del Estado». Si de esa identificación resultase la no colindancia, se practicará la inscripción haciéndolo constar. Si pese a tal identificación o por no poder llevarse a efecto, el Registrador sospechase una posible invasión del dominio público, pondrá la solicitud de inscripción en conocimiento de la Administración del Estado, dejándola en suspenso hasta que ésta expida certificación favorable.

41 Lógicamente, si los terrenos o parte de ellos estuvieran incluidos en un deslinde previo, se denegará la inmatriculación o inscripción del exceso de cabida, artículo 33-1 RC. El artículo 34-4 añade que el registrador practicará la inscripción solicitada cuando el título presentado testimonie o se acompañe de certificación expedida por el Servicio de Costas, acreditando que la finca no invade el dominio público, siempre que ello no contradiga ningún asiento de deslinde inscrito o anotado, en cuyo caso será necesario proceder previa o simultáneamente a su rectificación.

Si el bien intersecta la servidumbre de protección, se debe acreditar la no colindancia o invasión del demanio marítimo-terrestre. A mi juicio, si el bien se solapa en todo o en parte con la servidumbre de protección marcada en un deslinde ya aprobado, en principio no hay problema; porque se acredita que el bien queda fuera del demanio. Por tanto, la remisión a lo indicado en los preceptos siguientes RC, que efectúa el artículo 33-3, sólo tendría sentido cuando el deslinde todavía no hubiera sido aprobado. Así se desprende, por lo demás, del artículo $34 \mathrm{RC}$, que regula una serie de cautelas para los casos en que no exista deslinde. No obstante, el apartado primero establece asimismo prevenciones para el caso en que existe deslinde pero aún no consta su inscripción o anotación; ya que entonces el Registrador no puede saber si la finca invade o no el dominio público o si se halla en zona de servidumbre de protección —en este segundo caso cabría la inscripción, haciéndose constar este dato—. Vid. asi- 
Éste es el único precepto de la LC en que podría apoyarse en apariencia el TS para justificar la posibilidad de revisión permanente de los deslindes, ya que el artículo 15-4 debe ponerse en relación con los apartados anteriores ${ }^{42}$. Así, si no existe deslinde, la solicitud de inmatriculación se paraliza. A sensu contrario, podría entenderse que, si ya hay deslinde, como pese a ello el Registrador debe solicitar certificación negativa a la Administración en relación con los terrenos que, conforme al mismo, colindan con la ribera del mar, ello será porque puede que el deslinde previo sea incompleto o insuficiente; y que por tanto debe complementarse.

Ahora bien, el precepto, por una parte, no indica el procedimiento para complementar el deslinde anterior - no dice que el procedimiento sea el aplicable para aprobar el deslinde; o, por el contrario, la revisión de oficio ex artículo $9 \mathrm{LC}^{43}$ - ni sus consecuencias. Pero, además, el artículo 15 regula la inmatriculación de terrenos no inscritos previamente. No se refiere a terrenos ya inscritos en el Registro y excluidos de un previo deslinde ${ }^{44}$. Por otra parte, del artículo 34-1 RC se desprende

mismo artículo 35, para los casos en que la finca intersecte con la servidumbre de protección. En estos supuestos, la duda que justifique la suspensión de la inscripción puede deberse a no estar clara la ubicación real de la finca cuya inmatriculación o inscripción de exceso de cabida se pretende. Esto también, lógicamente, sería aplicable a los casos del artículo 34, aun si existiera deslinde.

42 El artículo 15-4 se complementa con el artículo 34-2 RC. De acuerdo con éste, si la zona a la que se refiere la solicitud de inmatriculación o de inscripción del exceso de cabida no estuviera deslindada, se iniciará el deslinde en el plazo máximo de tres meses, quedando entretanto en suspenso la inscripción. El Servicio de Costas comunicará esta circunstancia al Registro en mes siguiente a la recepción de la petición del registrador y se prorrogará la anotación de suspensión por un máximo de cuatro años, quedando el asiento practicado supeditado a la resolución del expediente de deslinde. Iniciado el expediente, el Servicio de Costas notificará al Registro la fecha del acuerdo de incoación y de su publicación, así como el plano con la delimitación provisional afectante a la finca, indicándose tales circunstancias por nota marginal. El titular a cuyo favor resulte anotado el dominio habrá de ser notificado en el expediente de deslinde.

43 El recurso extraordinario de revisión por error de hecho no tendría sentido, salvo que se verificara a través del ejercicio de la acción pública del artículo 109 LC.

44 El artículo $36 \mathrm{RC}$, relativo a segundas o posteriores inscripciones, indica que, si la finca intersecta con el demanio ya deslindado, debe denegarse el asiento; y Costas debe solicitar la anotación preventiva o la inscripción del deslinde —según haya transcurrido o no el plazo de cinco años-. El artículo 36-1 alude a los casos en que existe deslinde inscrito o anotado respecto de otras fincas de la zona, y de ese deslinde resulte que la finca cuya segunda o posterior inscripción se pretende es demanial; en tal caso se deniega la inscripción y se comunica a Costas para que solicite la rectificación de los asientos contradictorios con el deslinde. Es decir, en ambos casos existe deslinde, pero en todo o en parte todavía no consta en el Registro. Si la zona no ha sido deslindada, conforme al artículo 36-4 la segunda o posterior inscripción queda en suspenso a resultas del deslinde. Los apartados tercero y cuarto, relativos respectivamente al caso en que existe deslinde y a tramos de costa no deslindados, deben ponerse en relación con el segundo, referente a la solicitud de certificación cuando de la documentación gráfica pueda deducirse que la finca invade dominio público; en cuyo caso se practica anotación preventiva en vez de inscripción, a resultas de lo que indique la certificación o de lo que finalmente resulte del deslinde. Pero, desde luego, del artículo 36 no se 
que las cautelas indicadas en los primeros apartados del artículo 15 LC, se refieren a los casos en que hay deslinde ${ }^{45}$ pero no ha sido aún inscrito ni anotado, así que el Registrador desconoce en qué medida el deslinde puede afectar a las fincas objeto de la solicitud; o bien existen dudas sobre su ubicación o lindes. En suma, del artículo 34-1 RC se desprende, a sensu contrario, que las cautelas del artículo 15 LC son innecesarias si el deslinde consta en el Registro y se conoce la exacta ubicación de la finca.

Lo que hace el artículo 15 es establecer una cautela: se trata de terrenos en que no existe aún protección registral, más allá de lo indicado en el artículo 32 LH. Lo que se pretende es que no se inmatriculen terrenos que luego puedan resultar demaniales. Aun así, la norma no responde a la siguiente pregunta: ¿y si el terreno se excluye del deslinde practicado conforme al artículo 15-4, o se certifica negativamente su pertenencia al demanio; y luego resulta que reúne los caracteres propios de éste? ¿En qué situación queda quien ha inmatriculado el bien? $\mathrm{O}$, lo que es lo mismo, expedida certificación negativa o practicado el deslinde ex artículo 15-4, y habiéndose inmatriculado el bien conforme a la solicitud del particular, el posterior deslinde que sin más incluya el bien en el demanio, ¿no infringirá el buen funcionamiento del sistema registral; e incluso, en ciertos casos, la confianza legítima? Esto, a mi juicio, puede deducirse del artículo 30-3 RC, que indica que la aprobación del deslinde comporta la cancelación de las notas marginales, relativas a las fincas o la parte de las mismas no incluidas en el demanio marítimo-terrestre en virtud de aquél ${ }^{46}$.

desprende en absoluto la posibilidad de suspender la práctica de una segunda inscripción porque un deslinde «esté mal hecho o sea incompleto».

45 De acuerdo con este precepto, cuando alguna finca colinde o intersecte con la zona de dominio público, conforme a la representación grafica suministrada por la Dirección General de Sostenibilidad de la Costa y del Mar y cuyo deslinde no figure inscrito o anotado, el registrador suspenderá la inscripción solicitada y lo comunicará el mismo día al Servicio de Costas, así como al presentante y al titular, tomando en su lugar anotación preventiva de la suspensión por noventa días. El Servicio de Costas expedirá certificación en el plazo de un mes desde la recepción de la petición del registrador, pronunciándose sobre si la finca invade el dominio público. Transcurrido dicho plazo sin que se haya recibido contestación, se procederá a la conversión de la anotación en inscripción.

46 Resalta la importancia de esas notas marginales el artículo 31-3 RC: «Tratándose de inscripciones contradictorias sobre fincas que, no obstante estar afectadas por un expediente de deslinde, no se haya hecho constar, por cualquier circunstancia, la incoación del mismo por nota marginal, así como la expedición de la correspondiente certificación de titularidad y cargas, a los efectos de su notificación por la Administración, sólo procederá su cancelación si media el consentimiento del titular registral o resolución judicial firme, salvo que se acredite su intervención en el procedimiento o la notificación personal en tiempo del mismo, de modo que haya podido ejercer sus derechos en la forma prevista legalmente, exigencia que es igualmente aplicable para los titulares de derechos constituidos sobre la finca y que hayan de cancelarse por ser incompatibles con el dominio público». 
En suma, de los preceptos que regulan las relaciones entre el deslinde y el Registro no se desprende que un deslinde pueda complementar otro anterior técnicamente defectuoso; ya que no se exige al Registrador solicitar certificación para inmatricular o inscribir el exceso de cabida - mucho menos, si se trata de segundas o posteriores inscripciones-de fincas colindantes con el demanio marítimo-terrestre ya deslindado con la única finalidad de que, a resultas de dicha solicitud, pudiera procederse a la "complementación» de aquel deslinde. Si ya se ha practicado el deslinde, la solicitud de certificación sólo tendrá sentido si existen dudas sobre la ubicación de la finca o sus lindes —es decir, sobre si la misma se superpone o no con el deslinde ya aprobado- o si ese deslinde no ha sido todavía objeto de inscripción o anotación.

\section{PROPIEDAD, SEGURIDAD JURÍDICA Y CONFIANZA LEGÍTIMA COMO LÍMITES A LA POSIBILIDAD DE «COMPLEMENTACIÓN» DE LOS DESLINDES YA PRACTI- CADOS}

Existen razones adicionales que justificarían el rechazo de la doctrina relativa a la posibilidad de modificación y «complementación» sin límites del deslinde de costas. En primer lugar, examinaremos la protección del derecho de propiedad en la jurisprudencia del TEDH; en particular, cuando existe amparo del Registro. Ello, por cuanto el deslinde implica transformar la propiedad en concesión; lo que no satisface las exigencias de la total indemnidad. En segundo lugar, los principios de seguridad jurídica y de protección de la legítima confianza. En relación con esto último, hay que aludir tanto a los casos en que el Registro confiere la máxima protección —adquisiciones amparadas en el artículo $34 \mathrm{LH}$, sobre bienes excluidos de un deslinde previo-como a los restantes - por ejemplo, aquellos en que, tras haberse expedido certificación negativa por parte de Costas, se procede a la inmatriculación o inscripción del exceso de cabida de la finca ${ }^{47}$.

47 Este último caso, a su vez, puede venir relacionado con la existencia de un deslinde previo, del que esos terrenos quedaron excluidos - aunque, como hemos visto, en este caso poco sentido tiene la solicitud de certificación; salvo que hubiera dudas sobre la ubicación de la finca o el deslinde no constara en el Registro-; si no ha habido deslinde previo, como se ha visto, debe procederse a su práctica y entretanto se suspende la inscripción solicitada. 
1. El derecho de propiedad y su protección registral como límites a la posibilidad de revisión permanente de los deslindes de costas

\section{A) Consideración preliminar: ¿es suficiente la concesión compen- satoria como indemnización?}

El pase de un terreno al demanio marítimo-terrestre implica la conversión de la propiedad en concesión. Si bien estas concesiones no pagan canon; y si bien la Ley 2/13 amplía los plazos y permite su transmisión entre vivos, a fin de conferirles mayor valor económico, el valor de la concesión no equivale al de la propiedad sobre el mismo bien. Ni desde la perspectiva del valor de mercado, ni de la utilidad para el titular - hay inversiones que no pueden amortizarse en el plazo concesional, sobre todo si ha transcurrido un tiempo considerable desde el otorgamiento de la concesión y la solicitud de prórroga-, ni desde la perspectiva de la carga afectiva para el propietario - no es igual transmitir al descendiente una propiedad que una concesión limitada en el tiempo.

La STC 149/91 afirmó que nos encontramos ante una expropiación legislativa, donde la concesión actúa como justiprecio ${ }^{48}$; pese a las crí-

48 Que estemos ante una expropiación es evidente. Resalta A. Boix PALOP (2004), Las convalidaciones legislativas, Iustel, Madrid, págs. 146 ss., que una cosa es la generalidad de la ley y otra su grado de abstracción: aunque la LC sea formalmente general, sus DD.TT. 1. ${ }^{\mathrm{a}}$ y $2 .{ }^{\text {a }}$ carecen de abstracción, ya que es posible concretar los casos a que son aplicables, al referirse a la situación existente en un puntual momento. E. GARCÍA DE ENTERRÍA (1996), «Las expropiaciones legislativas desde la perspectiva constitucional. En particular, el caso de la Ley de Costas», RAP, 141, págs. 137 ss., utiliza además el argumento del contenido esencial, a su juicio afectado por la conversión de la propiedad en concesión. Vid. también DESDENTADo DAROCA (2007: 90 ss.), quien duda que se trate de una expropiación legislativa; a su juicio, es el deslinde el acto que declara la necesidad de ocupación: vid. SSTS de 2-6-10 y 28-5-08. Si defendemos que el deslinde es constitutivo, el mismo será el acto por el que se haga efectiva la expropiación.

Vid. también G. Doménech Pascual (2012b), «Cómo distinguir entre una expropiación y una limitación de la propiedad no indemnizable», Indret, enero 2012; J. M. RoDRíGUEZ DE SANTIAGO (2008), «Las garantías constitucionales de la propiedad y de la expropiación forzosa a los treinta años de la Constitución española», RAP, 177, págs. 182 ss.; J. AgUdo GonZÁLEZ (2011), «Concepción estatutaria y propiedad inmobiliaria. O la crónica de la desvalorización anunciada del derecho fundamental a la propiedad privada», $R A P, 185$, págs. 33 ss.; J. R. PARAda VÁzouez (1990), «Evolución y crisis del instituto expropiatorio», Documentación Administrativa, 200, págs. 41 ss.; J. BARCELONA LloP (2013), Propiedad, privación de la propiedad y expropiación forzosa en el sistema del Convenio europeo de derechos humanos, CEPC, Madrid, pág. 56; del mismo, (2011: 63).

El TEDH, en sentencias como Spörrong, Mellacher, Lithgow contra Reino Unido, entre otras, considera que la expropiación implica un cambio de titularidad. Para BARCELONA LLOP (2013: 69 ss.), la privación de la propiedad implica un definitivo, irreversible y auténtico desapoderamiento; no la mera restricción de las facultades de goce y disposición, por intensa y grave que sea. 
ticas de GARCÍA DE ENTERRÍA ${ }^{49}$, para quien así no se logra la indemnidad del propietario, que siempre podría intentar completar su indemnización. Para el autor, ello deriva de la STC 149/91, que formula un juicio abstracto y además añade que los afectados siempre pueden impugnar judicialmente la conversión de la propiedad en concesión, y deducir las pretensiones que consideren. De aquí deduce, aun subrayando la poca precisión del TC — que apela a las circunstancias que puedan darse; sin concretar-, que entre esas pretensiones puede estar la de complementar la indemnización ${ }^{50}$; porque una cosa es el control abstracto de constitucionalidad y otra la adecuación de la indemnización en el caso.

El TC, al enjuiciar la constitucionalidad en abstracto de la suficiencia de la indemnización, tiene en cuenta la singularidad de los bienes expropiados y las limitaciones correlativas a los derechos de los propietarios; junto con el período concesional y la ausencia de canon. No obstante, DESDENTADo DAROCA ${ }^{51}$ señala que es muy difícil valorar en abstracto la suficiencia de la concesión compensatoria como justiprecio; ya que ello puede depender de factores como su transmisibilidad, la carga o no de demoler las construcciones a costa del concesionario a la extinción de la concesión; o incluso los usos preexistentes ${ }^{52}$.

49 GARCÍA DE ENTERRÍA (1996: 131 ss.), quien resalta que el TC seguramente estuvo influido por la STS, Civil, de 6-7-88, que afirma que el Estado nunca pudo haber transmitido la propiedad plena de terrenos en zona marítimo-terrestre, sino sólo un dominio degradado o derecho real atípico — critican esta sentencia M. DEL P. RODRÍGUEZ GonZÁLEz (1998), «Reconocimiento de titularidades privadas en dominio público marítimo-terrestre. Alcance y límites», $R A P, 146$, págs. 239 ss.; SÁNCHEZ DE LAMAdRID AgUILAR (1989), «Un nuevo paso jurisprudencial en la contemplación del dominio público marítimo terrestre», La Ley, Madrid, 17-1189-. Vid. también Desdentado Daroca (2007: 176 ss.). Como señala García de EnTERría (1996: 151), en ciertos supuestos la Sala Primera ha reconocido propiedades privadas anteriores a la Ley 22/88 - a través de acciones declarativas de dominio con el referente en un momento del pasado.

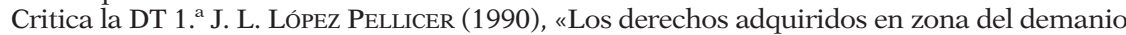
marítimo terrestre en la nueva Ley de Costas», REDA, 68, págs. 556 ss. Para J. L. MEILÁN GIL (1996), «El dominio público natural y la legislación de costas», RAP, 139, págs. 38 ss., lo criticable es la interpretación del TC. Sobre el tema, J. BARnes VÁzouEz (1990), «La ley de Costas y la garantía indemnizatoria», RAnAP, 2, págs. 81 ss.; M. GARCíA PÉREz (1995), La utilización del dominio público marítimo terrestre. Estudio especial de la concesión demanial, Marcial Pons, Madrid, págs. 347 ss.

50 (1996: 146). Vid. asimismo E. Desdentado Daroca (2011), «La difícil situación jurídica de las actividades económicas ubicadas en antiguas marismas: análisis crítico y propuestas de solución», RAP, 186, pág. 219. También GonZÁlez SALINAS (2000: 138 ss.) cuestiona la suficiencia de la concesión como indemnización. GARCíA DE ENTERRÍA (1996: 148 ss.) entiende que el control judicial de la suficiencia de la indemnización en los casos concretos debería articularse vía responsabilidad patrimonial.

51 (2007: 180 ss.). Vid. asimismo GARcía DE ENTERRía (1996: 147).

52 En todo caso, la STS de 14-7-03 señala: «... sin que tenga razón alguna el recurrente cuando afirma que la compensación, que le otorga tal DT, no puede serle aplicable porque no existía un uso o aprovechamiento específicos al tiempo del deslinde que pueda ser objeto de concesión administrativa, pues dicha norma transitoria le permite obtener una concesión de los usos o aprovechamientos de que sea susceptible el suelo por el período establecido en la 
La conversión de la propiedad en concesión no satisface el principio de indemnidad. Señala acertadamente DesDEnTADo DAROCA ${ }^{53}$ que la Ley 2/13 lo pone de manifiesto, ya que a consecuencia del reintegro en principio habría que devolver, como en la reversión, el justiprecio, esto es, la concesión; pero tal devolución será ficticia porque su objeto sería un derecho real limitado sobre el bien a revertir. De hecho, el otorgamiento de la concesión compensatoria es más bien una simple moratoria en la ocupación del bien por el Estado.

Como he resaltado en otro lugar ${ }^{54}$, lo más respetuoso habría sido expropiar por su equivalente económico todos los terrenos de la ribera del mar, que forman parte del demanio marítimo-terrestre por previsión constitucional ${ }^{55}$; y mantener enclaves privados en el resto de los integrantes de dicho demanio, como alternativa a lo anterior. Pensemos que los afectados o sus causantes adquirieron los bienes legítimamente - bien porque al tiempo de la adquisición no eran demaniales ni lo habían sido nunca; bien porque se desafectaron por un acto de soberanía- ${ }^{56}$; ello es importante porque, como afirma REVUELTA PÉREz ${ }^{57}$, el artículo 17 de la Carta de derechos fundamentales de la Unión Europea protege la propiedad de los bienes legítimamente adquiridos.

El TC, sin embargo, siguiendo la estela de la STC 166/86, vino a decir que el artículo 33.3 CE sólo garantiza la «correspondiente indemnización»; sin que ello exija total equivalencia con el valor del bien. Pero, sin que sea preciso elucubrar sobre qué significa «valor del bien» - valor intrínseco, valor de mercado...-, en cuanto el valor de la concesión es inferior per se al de la propiedad, el significado mismo del término «indemnización» debería implicar que el expropiado

misma norma, de modo que se respeta lo establecido en los arts. 9.3 y $33 \mathrm{CE}$, al no producirse una incautación sino la privación de una situación de hecho mediante la aludida compensación». La adquisición en su momento legítima de una propiedad en ningún caso puede dar lugar a una mera situación de hecho.

53 E. Desdentado Daroca (2014), «La reforma de la Ley de costas por la Ley 2/13: ¿una solución adecuada al problema de los enclaves privados?», RAP, 193, págs. 62-63 ss.

54 (2014: 496).

55 Así, J. Moreno Cánoves (1990), Régimen jurídico del litoral, Tecnos, Madrid, págs. 126 ss. Ésta es la solución ofrecida por DESDENTADo DAROCA (2011: 193 ss.), en relación con las actividades económicas ubicadas en terrenos ganados al mar o marismas en virtud de concesión, sin transmisión de la propiedad, anterior a la Ley 22/88.

56 Así, Desdentado Daroca (2007: 59). Por supuesto, pueden darse otras situaciones, en que no exista en el origen una adquisición legítima de un verdadero derecho de propiedad.

57 I. Revuelta Pérez (2012), «La ponderación del derecho de propiedad en la ejecución de sentencias urbanísticas», en Liber Amicorum Tomás Ramón Fernández, Civitas-Thomson, Madrid. Vid. sus argumentos sobre la aplicabilidad del artículo 17, pese a que en apariencia no esté en juego el Derecho europeo en el caso concreto. De la misma, (2011), «Demoliciones urbanísticas y buena fe dominical», Urbanismo y Edificación, 24, págs. 97 ss. 
quede indemne, sin matización ${ }^{58}$; aunque el TC haya relativizado esta idea $^{59}$.

Esta doctrina del TC tiene, en apariencia, su apoyo en la jurisprudencia del TEDH. En ciertos casos, éste permite que el justiprecio no consista en el equivalente económico exacto de los bienes expropiados, sino entiende bastante una relación de proporcionalidad y equilibrio razonable ${ }^{60}$. Así, en Ruspoli no considera vulnerado el derecho de propiedad si la Administración, conforme a la ley interna, ejercita el derecho de tanteo sobre un bien de interés cultural y demora su pago dos años sin intereses. Incluso, CIERCo SEIRA ${ }^{61}$ recuerda que la STEDH, Gran Sala, Jahn contra Alemania, excepcionalmente reconoció la legitimidad de una expropiación sin indemnización ${ }^{62}$.

58 No obstante, la doctrina entiende que la indemnidad total del expropiado tiene dudosa raigambre constitucional; véanse CIERCO SEIRA (2015: 126) y DOMÉNECH PASCUAL (2012a: 59 ss.). Vid. asimismo RodRíGUEZ DE SANTIAGo (2008: 157 ss.). Para este autor (2008: 188 ss.), que alude a la STC 166/86, una cosa es el "proporcional equilibrio» y otra exigir simplemente que no se excluya la indemnización o que la misma no esté manifiestamente desprovista de una base razonable; lo que considera insuficiente.

59 Así, STC 141/14: «en principio y en abstracto, puede ofrecer un proporcional equilibrio entre el daño sufrido y la indemnización correspondiente, en línea con la doctrina del TEDH (SSTEDH de 24-4-03, caso Yıltas Yildız. Turistik Tesisleri A.S. contra Turquía, y de 6-12-11, caso Anastasakis contra Grecia)».

En otro contexto, critica la relativización del derecho de propiedad en la doctrina del TC Agudo GonZÁLEZ (2011: 9 ss.).

60 Vid. Barcelona Llop (2011: 49 ss.); Doménech Pascual (2012a: 63); J. A. Carrillo doNAIRE (2011), «La garantía expropiatoria a la luz del CEDH», en F. LóPEz MENUdo (coord.), Homenaje a Alfonso Pérez. Moreno, Iustel, Madrid, págs. 455 ss.; F. González BotiJa (2011), «Reciente jurisprudencia del TEDH sobre expropiación forzosa», Urbanismo y Edificación, 23, págs. 71 ss.; E. GARCÍA DE ENTERRÍA (1990), «Las garantías de la expropiación según el Derecho europeo", Documentación Administrativa, 222, págs. 23 ss., para quien la reserva formulada por España no tiene sentido, ya que la protección conferida por la CEDH al derecho de propiedad no es superior a la prevista en la CE.

La STEDH Ucieza contra España indica: «Con el fin de determinar si la medida litigiosa respeta la deseada justa ponderación y, especialmente, si no hace recaer sobre el demandante una carga desproporcionada, hay que tomar en consideración las modalidades de indemnización previstas por la legislación (Ex-Rey de Grecia y otros c. Grecia [GC]).

76. Sin la satisfacción de un importe que esté razonablemente en relación con el valor del bien, una privación de propiedad constituye normalmente una vulneración excesiva que no puede justificarse en el ámbito del art. 1. Sin embargo, este último no garantiza el derecho a una compensación integral en todos los casos, pues unos objetivos legítimos de "utilidad pública” pueden incidir en una compensación inferior al completo valor mercantil (ver, entre otras, Papachelas c. Grecia [GC]). Una privación de propiedad carente de indemnización puede, en ciertas circunstancias, ser conforme al artículo 1 (Jahn y otros c. Alemania [GC])». Vid. asimismo Jokela c. Finlandia. También el TJUE, así en Krizan, afirma que caben restricciones a la propiedad por razones de interés general reconocidas en el Derecho de la Unión, como la protección ambiental; pero siempre que, a la vista del objetivo perseguido, no constituyan una intervención desmesurada e intolerable que afecte a la esencia del derecho. Recordemos que, para GARCÍA DE ENTERRÍA (1996: 137 ss.), la conversión de la propiedad en concesión afecta al contenido esencial.

61 (2015: 127).

62 Asimismo, de modo incidental, Pressos y Santos Monasterios, así como Ex-Rey de Grecia, citadas por BARCELONA LLOP (2011: 71). La STEDH Jahn —criticada por el autor (2013: 
Ahora bien, esta doctrina del TEDH que exige sólo una indemnización equilibrada y razonable no se refiere a cualquier expropiación, sino a aquellas en que el interés general ínsito en la causa expropiandi es de tal índole que exige o justifica modular la cuantía del justiprecio ${ }^{63}$. Así, en Vistins afirma que en muchos casos de expropiación lícita, como para construir una carretera, sólo una indemnización integral resulta razonable — también en Di Marco ${ }^{64}$ _. Y en Scordino (Gran Sala) se trataba de una expropiación aislada, que no obedecía a medidas de reforma económica, social ni política, ni se aducía ninguna otra circunstancia particular; por lo que no se apreció ningún motivo de utilidad pública que justificara una indemnización inferior al valor de mercado.

191 ss.) - revoca la dictada en Sala en 2004; sobre ésta, L. DíEz-PicAzo y Ponce DE LEÓN (2004), « ¿Hay que indemnizar las privaciones generales de propiedad?», Revista Española de Derecho Europeo, 12, págs. 597 ss.

63 Vid. Barcelona Llop (2013: 197 ss., y 2011: 73), para quien la modulación de la indemnización no ha de enmarcarse en un contexto excepcional, pero sí suficientemente caracterizado; como una reforma social o medidas justificadas de política económica; nacionalizaciones — citando el caso Lithgow —; o modulaciones debido al estado de las finanzas estatales; o casos en que el bien fue adquirido del Estado después de que éste lo hubiera confiscado a otras personas, a quienes procedía su devolución. En Lithgow se consideró que el alcance de la indemnización puede ser diferente según estemos ante una nacionalización o ante una expropiación singular; vid. GARCíA DE ENTERRÍA (1990: 31 ss.), quien subraya el margen de apreciación que el TEDH reconoce a los Tribunales nacionales.

Vid. asimismo D. UtRILla FeRnÁnDEZ-BERMEJo (2011), Las garantías del derecho de propiedad privada en Europa. Derecho de la Unión Europea y Convenio Europeo de Derechos Humanos, Civitas, Madrid, págs. 59 ss. Para BARCELONA LLOP (2011: 77), el TEDH no exige aplicar la alternativa menos gravosa; así que la proporcionalidad de la medida se resuelve en la proporcionalidad de la indemnización. Para el autor (2013: 128 ss.), el control de proporcionalidad del TEDH no es tal, sino más bien un control de «desproporción»; lo que critica porque una cosa es la deferencia a la apreciación estatal de la causa que legitima la expropiación y otra la deferencia sobre la necesidad del medio empleado.

Vid. también J. BARNÉs VÁzouez (1995), Propiedad, expropiación y responsabilidad. La garantía indemnizatoria en el Derecho europeo y comparado, Civitas, Madrid; E. MENÉndez SEBASTIÁN y L. TOLIVAR Alas (2009), «El derecho de propiedad desde la perspectiva del TEDH», en Homenaje al Prof. Dr. Lorenzo Martín-Retortillo, vol. II, El Justicia de Aragón, Zaragoza, págs. 1797 ss.

64 Es significativo el voto particular de GonZÁLEZ RIVAS a la STC 141/14: «El TEDH ha utilizado la expresión "equilibrio justo" entre las exigencias del interés general y los imperativos de los derechos fundamentales de la persona, y así, en STEDH de 9-10-03 (Federici c. Italia), contiene la expresión "pago de la cantidad razonablemente relacionada con el valor del bien" y utiliza el concepto de "pleno valor de mercado" para el caso de expropiaciones — como las urbanísticas - no inspiradas en motivos de justicia social o de reforma económica, expresando que para casos como "la expropiación de un terreno para la construcción de una carretera o para otros fines 'de utilidad pública', tan sólo la indemnización íntegra puede ser considerada como razonablemente proporcionada con el valor de un bien”. Esta regla tampoco carece de excepción [Ex rey de Grecia y Otros c. Grecia (justa satisfacción) (GS)].

También reconoce dicha jurisprudencia que los objetivos legítimos de "utilidad pública”, son aquellos que persiguen las medidas de reforma económica o de justicia social y pueden requerir un rembolso inferior al pleno valor de mercado (STEDH 26-4-11, Di Marco c. Italia, ap. 61).

De esta doctrina parece desprenderse claramente que el justiprecio debe reflejar el valor real —de mercado- de los terrenos...». 
En cambio, en Papachelas se afirma que la indemnización expropiatoria para construir una carretera es adecuada porque sólo quedaba 1.621 dracmas por metro cuadrado por debajo del valor de tasación; es decir, como la diferencia era irrisoria, no se habría lesionado el Protocolo. De hecho, para BARCELONA LloP ${ }^{65}$ el tema no está cerrado, ya que en las sentencias estimatorias que analiza, la indemnización había sido inferior a la mitad del valor del bien; y sujeta a tributación ${ }^{66}$.

Por otra parte, en las expropiaciones legislativas cuya causa es el mandato constitucional de demanialización de la costa, existe un interés general de primer orden que podría justificar la modulación del justiprecio, a la luz de la doctrina del TEDH; sobre todo, considerando la inviabilidad económica de una expropiación ordinaria y la mejora del régimen concesional tras la Ley 2/13. Para la STEDH Kozacioglu, no es preciso que el justiprecio equivalga al valor de mercado cuando la expropiación sea por una causa de interés general como la condición de

65 (2013: 210). Así, cita los casos Di Marco y Serino, de 2011 y 2010, donde de nuevo se apela al criterio de la desproporción. La STEDH Di Marco afirma: «Dans la présente affaire, comme il est déjà établi que l'ingérence litigieuse satisfaisait à la condition de légalité et n'était pas arbitraire, une réparation non intégrale ne rend pas illégitime en soi la mainmise de l'État sur les biens du requérant. Dès lors, il reste à rechercher si, dans le cadre d'une privation de propriété licite, le requérant a eu à supporter une charge disproportionnée et excessive (voir, mutatis mutandis, Scordino (no 1), précité)». En ese caso se había vulnerado el artículo 1 del Protocolo porque la indemnización era seis veces inferior al valor de los bienes; además, no se había considerado que la expropiación privaba al demandante de los medios para trabajar. De todos modos, la sentencia es algo contradictoria, ya que empieza diciendo que aun en expropiaciones lícitas muchas veces es exigible una reparación integral; para luego añadir que, en el caso concreto, siendo lícito el fin de la expropiación, la misma no sería ilegítima por el solo hecho de no efectuar una reparación integral, sin plantearse si la causa de la expropiación era particularmente relevante o no; aunque posiblemente se esté haciendo referencia únicamente a la licitud de la causa de la expropiación. Como un ejemplo en que el TEDH exige la plena indemnidad del expropiado, CIERCo SEIRA (2015: 137) cita la STEDH Lallement contra Francia.

La STEDH Vistins, de 25-10-12, expropiación de una isla que pasaba a ser zona portuaria, entiende que existe una manifiesta e injustificada desproporción; ya que el justiprecio se reducía al cinco por ciento del valor del bien y luego al valor catastral que tenía en 1940 aumentado conforme al IPC, lo que arrojaba un resultado irrisorio. El 25-3-14, la Gran Sala ha reducido el montante de la indemnización por entender que la expropiación en sí no era ilegal; si bien mantiene la desproporción del precio pagado.

Utrilla FernáNDEZ-Bermejo (2011: 77 ss.) apunta la utilización del artículo 41 CEDH ante las insuficiencias de la mera «indemnización equitativa» en el caso concreto; es decir, la posibilidad de que la responsabilidad patrimonial sirva de cláusula de cierre, al considerar que la garantía expropiatoria no se puede extender artificialmente. Así, cuando se inflija una carga excesiva que rompa el justo equilibrio, podría acudirse a la responsabilidad patrimonial. Esto es relevante cuando pueda haberse infringido la seguridad jurídica o la confianza legítima, como veremos.

66 En algún caso, además, el TEDH tiene en cuenta la licitud de la expropiación en cuanto a la causa y el procedimiento para determinar la adecuación de la indemnización; de modo que, si la expropiación es lícita, en ocasiones acude a este argumento para justificar la modulación de la cuantía de la indemnización. 
bien de interés cultural; siempre que ello no implique una carga excesiva para el propietario ${ }^{67}$.

Ahora bien, que la transformación de la propiedad en concesión pueda satisfacer, por hipótesis, las exigencias de indemnización equitativa, proporcionada y razonable, al constituir la demanialización de las costas un imperativo de primer orden, no puede hacernos olvidar que ello no constituye, ni aun tras la Ley $2 / 13$, el equivalente económico de la propiedad. Así, es preciso hacer entrar en juego una constante en la doctrina del TEDH: la especial protección que al derecho de propiedad confiere el Registro de la Propiedad, y sus consecuencias ${ }^{68}$.

\section{B) La incidencia de la protección registral de la propiedad a la luz de la jurisprudencia del TEDH}

Esta consideración tiene particular incidencia sobre el problema que nos ocupa. Puede, en primer lugar, que un bien, situado en un tramo del litoral ya deslindado y excluido del deslinde, se inmatriculara a favor de un particular, tras haberse agotado las cautelas previstas en la LC y el RC; y, más tarde, se revisara el deslinde y se declarara demanial. Ello sería especialmente grave si la inmatriculación se practica a solicitud del adquirente a título oneroso; puede que el interesado en adquirir el bien se haya cerciorado previamente de su carácter no demanial, y se vea sorprendido después por la revisión del deslinde previo. $\mathrm{O}$ pensemos en un tramo ya deslindado, donde un bien ha quedado fuera del deslinde; que, constando el mismo a nombre de un particular, un tercero lo adquiera bajo la protección del artículo $34 \mathrm{LH}$; y que finalmente se incluya en la revisión del deslinde previo. $\mathrm{O}$ en la adquisición de un bien al Estado e inscripción a favor del adquirente; si después el bien se declara demanial y esa demanialidad no se hubiera podido conocer por el comprador.

67 En ese caso, el edificio se había expropiado por su interés cultural, pero la normativa establecía que ello no se puede considerar para aumentar el justiprecio; en cambio, si ese interés cultural disminuye su valor, tal disminución sí debía tenerse en cuenta. Aunque admite que la protección del patrimonio cultural pueda modular la cuantía indemnizatoria, el TEDH entiende que la regulación turca, así considerada, no es equitativa porque el Estado siempre sale con ventaja; y que se debe tener en cuenta razonablemente lo que el interés cultural del bien supone a la hora de determinar su valoración. El TEDH fijó una indemnización ex artículo $41 \mathrm{CEDH}$; pero menor que la que habría correspondido a la diferencia con el valor real porque la expropiación tenía base legal y sólo el justiprecio era desproporcionadamente bajo. Para BARCELONA Llop (2013: 204), ello se debe a la dificultad de calcular el valor histórico.

68 Véase J. M. Díaz Fraile (1991), La protección registral del litoral, Centro de Estudios Registrales. Asimismo, J. C. Villalón Prieto (2009), «Protección de la propiedad, urbanismo y ordenación del territorio en la última jurisprudencia del TEDH», REDA, 142, págs. 343 ss. 
Para el TEDH, si un terreno goza de protección registral, la privación de la propiedad exige en todo caso una indemnización equitativa. Así, en Emiroglu, Yildirir ${ }^{69}$ y Curmi —donde se añade que la desproporción puede provenir de la demora excesiva en la obtención de la indemnización, lo que constituye un adicional perjuicio-; así como Koktepe $^{70}$. En Turgut subraya la buena fe de los demandantes y el hecho de que existiera una cadena registral desde 1911; por lo que lesiona la seguridad jurídica y el derecho de propiedad la anulación judicial, sin indemnización alguna, de su título de propiedad y su inscripción, para inscribir a nombre del Estado por tratarse de dominio público forestal ${ }^{71}$. En $N A$ c. Turquía afirma también que vulnera la propiedad la demolición, sin indemnización, de un hotel situado en el demanio marítimo-terrestre ${ }^{72}$. En ese caso, el bien se había adquirido legítimamente conforme al Registro; para el TEDH, estamos ante una privación ${ }^{73}$.

69 Indica BARCELONA LLOP (2013: 71) que en este caso la indemnización no se enfocó desde la perspectiva del derecho de propiedad, sino a partir del mal funcionamiento del Registro.

70 Esta última resulta muy significativa, ya que afirma que la remisión del perjudicado a un procedimiento posterior de responsabilidad patrimonial no supera el test del recurso efectivo - vid. I. Revuelta Pérez y E. NARbón LAinez (2010), «Ejecución de sentencias en materia urbanística, demolición y terceros adquirentes de buena fe. El caso de la anulación de licencias», $R C D I, 720$, págs. 1625 ss.- . De ahí la importancia de la Ley $2 / 13$, que en gran medida equipara a los titulares afectados por la DT 1-2 con quienes hubieran obtenido sentencia firme a su favor; ya que desde ahora no será ya necesario acudir a una acción civil declarativa de dominio - tras el recurso contra el deslinde y con carácter previo a otro posible recurso en relación con las condiciones de la concesión-para poder tener derecho a la concesión.

En Köktepe, además, se llega a tal conclusión aunque, como señala BARCELONA LLOP (2013: 67 ss.), la privación de la propiedad aún no se había producido; se entendió, no obstante, existente una injerencia desproporcionada en el derecho al respeto a los bienes. Para el autor, op. cit., pág. 184, lo determinante no fue sólo la ausencia de indemnización, sino esto unido a la inviabilidad de combatir judicialmente el deslinde.

71 En Rimer, asimismo, estima vulnerado el artículo 1 del Protocolo, al haber pasado el terreno del demandante, sin indemnización, al dominio público forestal. En Ansay, en cambio, la demanda se inadmitió; ya que la consideración forestal de los terrenos, aunque impedía el uso urbanístico, era compatible con la propiedad privada; además de que desde 1942 el Catastro había afirmado su carácter forestal, confirmado cincuenta años después, sin que en su día los demandantes hubieran reaccionado. Similar conclusión, aunque entró en el fondo, en Lazaridi contra Grecia.

72 Estudian esta jurisprudencia Revuelta Pérez y NARbón LAINEz (2010: 1595 ss.). Vid. Revuelta PÉrez (2012); la autora insiste en que nuestro Ordenamiento exige ponderar la buena fe. De la misma, (2011: 97 ss.).

Vid. asimismo sentencias Dogrusoz y Hüseyin Ak, sobre supuestos de integración justificada del bien en el demanio marítimo-terrestre pero sin indemnización sustitutiva. Asimismo, el caso Mehmet Ali.

73 Vid. también SSTEDH Depalle y Brosset-Triboulet. Aunque los recurrentes no ostentaban la propiedad ni gozaban de la protección registral de un derecho de propiedad, el TEDH analiza cuidadosamente su situación para evitar que su derecho concesional finalizara de modo desproporcionado. Vid. F. González Botija y V. SANZ Gómez (2010), «De las órdenes de demolición de viviendas residenciales construidas en el demanio marítimo: a propósito de las 
Más recientemente, la STEDH de 4-11-14, Ucieza, entiende lesionada la propiedad porque, inscrito un terreno en que existía una iglesia a favor de una mercantil - que tenía la condición de tercero conforme al artículo $34 \mathrm{LH}^{74}$-, se inscribió la iglesia a favor del Obispado, con base en la certificación expedida por la autoridad eclesiástica ex artículo $206 \mathrm{LH}^{75}$. La demanda se estima aunque España aducía que la inmatriculación no es título de propiedad, sino sólo un título de inscripción impugnable judicialmente - como de hecho había procedido el actor, sin éxito- ${ }^{76}$. Ello es importante: como se ha visto, la doctrina del TS sobre la revisión del deslinde de costas se basa en su carácter «declarativo", cuando el deslinde tiene clara incidencia sobre los asientos registrales ${ }^{77}$.

La sentencia muestra la importancia del Registro en la protección de la propiedad: insiste en que el bien estaba previamente inscrito a nombre del demandante y en que el artículo 206 LH sólo juega en ausencia de inscripción previa. En todo caso, para el TEDH, estamos ante el primer inciso del artículo 1 del Protocolo; no se trataría de una expropiación, sino de una injerencia en la propiedad que, al no estar justificada, implicaba un ataque al derecho de todos al respeto de sus bienes.

sentencias del TEDH Brosset-Triboulet c. Francia y Depalle c. Francia, de 29-3-10», Urbanismo y Edificación, 22, págs. 239 ss. Para BARCELONA LlOP (2013: 70), aunque no estamos ante un derecho de propiedad, sí estamos ante un bien en el sentido del CEDH; y la previsión relativa a la "privación» comprende cualesquiera bienes y no sólo la propiedad, aunque en este caso se afirma que no hubo privación porque la demolición no se había producido. Esta noción amplia de «bien» es relevante. La DT 1-2 LC alude a bienes que tenían las características del demanio marítimo-terrestre con la Ley 28/69; pero no se incluyeron en el deslinde por existir títulos amparados en el artículo $34 \mathrm{LH}$, sin que haya sentencia firme civil que los hubiera declarado de propiedad privada en un momento histórico determinado —ello, frente a los casos de la DT 1-1, donde existe sentencia firme declarativa de un derecho histórico de dominio; y sobre todo a los de la DT 1-4, terrenos que pasan a demaniales tras la Ley 22/88; o del artículo 13 bis, cambio en la configuración de la costa-. Conforme a esta jurisprudencia, aun los casos de la DT 1-2 merecen protección.

En todo caso, para BARCELONA LLOP, la afirmación de que no hubo privación en Depalle porque la demolición aún no se había producido tiene poco sentido, ya que estamos ante una ocupación en precario; sin que tenga sentido hablar de "privación» en esos casos, ni tampoco en los de construcción ilegal. Así, op. cit., pág. 184, afirma que no es incorrecto que la legislación prevea la posibilidad de demolición sin indemnización en las autorizaciones en precario.

74 El argumento de la Audiencia estribaba en que la iglesia no era objeto de la inscripción a favor del demandante, ya que no habría formado parte de los bienes del Priorato en su día desamortizados. El TEDH, a la vista de la cadena de inscripciones, llega a la conclusión contraria.

75 La Ley 13/15 ha suprimido esta potestad de la Iglesia Católica.

76 El TEDH tuvo asimismo en cuenta la ausencia de indemnización, la infracción de la igualdad de armas, la inexistencia de un título de propiedad a favor del Obispado y las nulas posibilidades de defensa del demandante.

77 En efecto, el artículo 13 LC constituye, junto con otros como el artículo 8 de la Ley 3/95, una excepción al artículo 17 LH, que prohíbe la inscripción del título si preexiste una inscripción incompatible, aunque el título de ésta fuera posterior. 
Esta importancia del Registro a efectos del artículo 1 tiene interés. Suponiendo que la conversión de la propiedad en concesión sea en abstracto una indemnización "equitativa y proporcionada» a la finalidad de demanialización de la costa, sin embargo, debe acompañarse de garantías especiales cuando se trata de titularidades inscritas a favor de particulares. Es decir, si estamos ante títulos amparados en el Registro, podría pensarse que debe matizarse la idea de que basta una «compensación justa y equitativa» ${ }^{78}$; sobre todo, si existe una previa actuación administrativa de la que pueda racionalmente deducirse que los bienes no son demaniales, como su exclusión de un previo deslinde. Ello es así porque, para el TEDH, los incisos del artículo 1 relativos a la expropiación y a las limitaciones a la propiedad por motivos de interés general deben interpretarse a la luz del primero - el derecho al respeto de los propios bienes ${ }^{79}$ - . Quizá por esta razón, en ocasiones entiende excepcional que la compensación expropiatoria pueda no abarcar todo el valor de los bienes.

En efecto, en estos supuestos pueden defenderse dos soluciones. La primera, considerando la importancia que al TEDH merece la protección registral, que el derecho de propiedad se vulnera si la indemnización consiste sólo en una compensación razonable. El argumento estribaría en que estamos ante dos intereses públicos contrapuestos de primer orden: en nuestro caso, la exigencia constitucional de demanialización de la costa, por una parte; y, por otra, la seguridad del tráfico inmobiliario, garantizada por el Registro. Es decir, en el juicio de proporcionalidad y razonabilidad de la compensación deben ponderarse todos los intereses encontrados; y en este caso, frente a la demanialización de la costa, no sólo tenemos el interés privado del titular registral, sino también el interés general en la seguridad del tráfico inmobiliario. Esta solución no sólo se extendería a los casos en que se revisa un deslinde para incluir bienes excluidos del anterior, sino a todos en que el deslinde modifique asientos registrales; muy en particular, cuando el perjudicado sea un tercer adquirente amparado en el artículo 34 LH y merecedor de la protección registral al máximo nivel.

La segunda solución sería entender que, en principio, la demanialización de las costas es un interés público de primer orden, que legi-

78 En Emiroglu se entiende vulnerado el derecho de propiedad porque el actor la tenía inscrita en el Registro, pero luego su terreno fue declarado de dominio público litoral; sin que se procediera a su indemnización.

79 Sobre la estructura del precepto, SSTEDH Spörrong, Oxford, Draon, Jokela, Santos Monasterios; Potomski; Melo, entre otras; Scordino, que entiende que no existe privación de la propiedad en el caso; Depalle, que llega a igual conclusión. Vid. BARCELONA LLOP (2013: 33 ss.); del mismo, (2011: 53 ss.); Villalón Prieto (2009: 339 ss.). 
tima la expropiación a cambio de una indemnización proporcionada y razonable aun si estamos ante terrenos inscritos a favor de un tercero protegido por el artículo $34 \mathrm{LH}$; pero entendiendo que, si existen actos propios de la Administración de los que cabe legítimamente presumir que los bienes no son demaniales, su posterior inclusión en el demanio deberá rodearse de especiales garantías procedimentales ${ }^{80}$, y preverse indemnizaciones adicionales por la lesión, en su caso, de la legítima confianza. A ello me referiré más adelante.

En cuanto a la primera solución, si se entendiera infringido el derecho de propiedad cuando se incluyen en un deslinde terrenos hasta ese momento protegidos por el Registro sin garantizar la total indemnidad del propietario, esta conclusión no sólo se extendería a los casos en que se revisa un deslinde, sino también se aplicaría cuando se practicara ex novo en una zona hasta entonces no deslindada. Asimismo, la lesión se produciría cuando, debido a un cambio físico en la costa, los terrenos se deslindaran como demaniales; todo ello, salvo que se otorgara al antiguo titular el exacto equivalente económico; y cuando, debido a un cambio normativo, se incluyeran en el deslinde y no se reconociera el exacto equivalente económico como indemnización.

Hemos visto que, a mi juicio, lo más respetuoso con el derecho de propiedad - y coherente con la preservación de los valores naturales ínsitos en el demanio marítimo-terrestre- sería expropiar por el equivalente económico del valor de los bienes; o bien, como propugnaba GARCÍA DE ENTERRÍA ${ }^{81}$, otorgar la concesión sin perjuicio de reconocer indemnizaciones adicionales. Pero, por ahora, de la doctrina del TC y del TEDH no parece que podamos llegar a esta conclusión; pese a que en casos como éstos se enfrentan dos intereses públicos de primer orden. En efecto, veíamos que el TEDH ha reconocido en muchas ocasiones la infracción de la propiedad por la integración en el demanio de

80 Es significativa la alusión que Ucieza efectúa a las garantías procedimentales: «Cuando se trata de una injerencia en el derecho del demandante al respeto de sus bienes, los procedimientos aplicables deben también ofrecer a la persona afectada una oportunidad adecuada para exponer su causa a las Autoridades competentes con el fin de impugnar efectivamente las medidas que vulneren el derecho en cuestión. Una tal injerencia no puede tener legitimidad en ausencia de un debate contradictorio y respetuoso del principio de igualdad de armas, que permitan debatir sobre los aspectos relevantes para la resolución de la causa. Para asegurarse del respeto de esta condición, se deben considerar los procedimientos aplicables desde un punto de vista general (ver, entre otras, Jokela c. Finlandia, AGOSI c. Reino Unido, 24-10-86, Hentrich c. Francia, anteriormente citada, y Gáll...)».

81 (1996: 146). DESDENTADO DAROCA (2007: 176 ss.) cita, en el sentido apuntado por el primero, la STS de 7-6-04, que reconoce la posibilidad de solicitar indemnización adicional. En cambio, la STS de 10-12-09 desestima el recurso contra la desestimación de la reclamación presentada tras un deslinde previamente declarado conforme a Derecho. El TS afirma que, conforme a la STC 149/91, las concesiones de la DT 1. ${ }^{a}$ constituyen compensación suficiente; por lo que no hay confiscación ni infracción del derecho de propiedad. 
bienes registrados a nombre de particulares; pero en casos en que no había habido indemnización ${ }^{82}$. Por ejemplo, en Dögrusöz, los demandantes adquirieron un terreno que no constaba de titularidad pública. Tras su adquisición e inscripción registral, se deslindó como demanio marítimo-terrestre; tras ello, se ejercitó una acción civil que concluyó en la declaración de titularidad estatal. El TEDH afirmó que existía privación de la propiedad sin compensación; si bien, como de la ley se derivaba el carácter demanial de los terrenos, se acordó una indemnización ex artículo 41; aproximadamente la mitad de lo solicitado ${ }^{83}$.

En suma, actualmente la protección registral no justifica por sí sola el derecho a una indemnización integral, desde la perspectiva del Protocolo; aunque a su favor existe el argumento de la seguridad del tráfico inmobiliario como interés público de primer orden, que debe ponderarse con la causa expropiandi. Otra cosa es que afirmemos que esa indemnización integral deriva directamente de la $\mathrm{CE}$, en el sentido defendido por GARcía DE ENTERRÍA.

\section{C) La exigencia de indemnización integral en los casos de expro- piación ilícita}

Para el TEDH, siempre existe derecho a indemnización integral, por la totalidad del valor del bien y por todos los perjuicios sufridos, si la expropiación es ilegal. Entiende que estamos ante una expropiación ilegal tanto si la misma no queda amparada en una legítima causa expropiandi — si bien hay que tener en cuenta el amplio margen de apreciación de los Estados- como cuando no se ha seguido el procedimiento debido; como en caso de vía de hecho. En cambio, si la ilicitud estriba en la ausencia o insuficiencia de indemnización, afirma que la expropiación no resulta intrínsecamente ilícita; así que no siempre re-

82 Además, para el TEDH sólo existe propiamente garantía indemnizatoria ante una privación de la propiedad; aunque añade que, para otras injerencias desproporcionadas en dicho derecho, podría jugar el artículo 41. Nuestro caso, no obstante, sí constituye privación de la propiedad. Vid. BARCELONA Llop (2013: 56).

83 Además, resaltan Revuelta Pérez y Narbón Lainez (2010: 1609) que la doctrina hipotecarista suele afirmar que el artículo $34 \mathrm{LH}$ no protegería frente a la integración de los bienes en el demanio, ya que ello supondría la desaparición de la cosa como objeto de tráfico jurídico-privado, que es el protegido por el Registro. En todo caso, aducen contundentes argumentos a favor de la protección del tercero hipotecario frente a la anulación de la licencia del inmueble adquirido; la LO 7/15 modifica el artículo 108 LJCA, de modo que ahora se exige, una vez acordada la demolición del inmueble, que se garantice el pago de las indemnizaciones a los terceros de buena fe. Vid. asimismo Revuelta Pérez (2012). No obstante, no afirmo que el artículo 34 sea una barrera absoluta frente al dominio público, sino la posibilidad de ponderar la fe pública registral a la hora de cuantificar la indemnización. 
conocerá una indemnización integral —así, STEDH Di Marco—. Por ejemplo, en Dögrusöz señala que como el problema no radicaba en la ilegalidad de la privación en sí, sino en la falta de compensación, la indemnización no tenía que reflejar necesariamente todo el valor de la propiedad; por lo que concedió algo más de la mitad de lo solicitado, ya que lo indemnizable, para el TEDH, serían las legítimas expectativas frustradas ${ }^{84}$.

En nuestro caso - modificaciones sorpresivas de un deslinde previo, sin cambios normativos ni en las circunstancias fácticas- podría existir un punto de apoyo para entender vulnerado el artículo 1 del Protocolo. En efecto, la medida debe estar prevista en la ley interna para resultar legítima, de acuerdo con el TEDH y el propio precepto. Pues bien, aunque sea obligada la inclusión en el demanio marítimo-terrestre de los bienes que poseen sus características propias, a mi juicio, se infringen las garantías procedimentales establecidas en la normativa española cuando se procede de ese modo. En efecto, hemos visto que la LC sólo habilita la modificación del deslinde en caso de cambios normativos —así, la DT 1-3 y la 1-4 - o cambios físicos en la costa; sin que tenga sentido argumentar sobre el supuesto carácter declarativo de los deslindes o la ausencia de acto propio. Si es así, la injerencia en el derecho al respeto a los bienes será ilegítima por no estar prevista en la ley, al no respetarse las garantías procedimentales; y en tal caso el TEDH exige la reparación integral ${ }^{85}$. Es decir, los afectados, además de la concesión, podrían solicitar una indemnización adicional por la diferencia de valor entre aquélla y la propiedad de los bienes demanializados $^{86}$.

Otra cosa sería que se modificara la LC para permitir expresamente el deslinde cuando, por un error, resulte incompleto; si bien debería exigirse que, en el mismo acto de inclusión en el nuevo deslinde, se determinara la indemnización por infracción de la legítima confianza. En todo caso, veíamos que existen interpretaciones alternativas, con-

84 Indica BARCELONA Llop (2013: 53) que la indemnización de las legítimas expectativas se verificaría vía artículo $41 \mathrm{CEDH}$; y subraya que en Pressos fue más o menos la mitad de lo solicitado. En todo caso, op. cit., págs. 215 ss., añade que la ausencia de indemnización en caso de privación de la propiedad es un ilícito por sí misma, y no la consecuencia de un ilícito, que sería lo contemplado en el artículo 41; de modo que la indemnización debe fijarse vía artículo 1 del Protocolo y no vía artículo $41 \mathrm{CEDH}$, al menos conceptualmente.

85 Vid. Barcelona Llop (2013: 220), sobre la cuantía de la indemnización en estos casos.

86 Que los demandantes puedan defenderse judicialmente, intentando que se declare ilegal el deslinde o que en su día disfrutaron de un derecho de propiedad, tampoco es suficiente, ya que la CEDH, al exigir la legitimidad de la expropiación, reenvía al Derecho interno. Otra cosa es que, además, exista lesión de la propiedad si se vulnera la igualdad de armas: vid. Revuelta Pérez (2012). 
forme a las cuales en caso de cambio físico o normativo sería obligatorio el deslinde; pero sin que éste quede impedido en los restantes.

\section{La protección de la confianza legítima como límite a la modifica- ción de los deslindes}

Hemos visto que, salvo que entendamos ilícita la privación de la propiedad por infracción procedimental cuando, sin mediar cambios físicos ni normativos, se complementa un deslinde previo, o salvo que se acoja la plausible interpretación de GARCÍA DE ENTERRÍA sobre el complemento de indemnización en la concesión compensatoria, es difícil hoy por hoy defender el derecho a una indemnización integral; ni siquiera a la luz de la jurisprudencia del TEDH.

Sin embargo, existe otra salida si se modifica el deslinde sin haber mediado cambios físicos ni normativos. En efecto, el previo deslinde que ha excluido determinados bienes constituye un acto propio de la Administración. Y, cuando a la vista de ese acto propio los particulares han realizado gastos en los que de otro modo no habrían incurrido, se habrá lesionado la confianza legítima ${ }^{87}$.

87 Sobre ese principio, R. GARCía MACHO (1987), «Contenido y límites del principio de confianza legítima: estudio sistemático de la jurisprudencia del Tribunal de Justicia», REDA, 56; F. Castillo Blanco (1998), La protección de la confianza en el Derecho Administrativo, Marcial Pons, Madrid; J. GARcía LuENGo (2000), El principio de protección de la confianza en el Derecho Administrativo, Civitas, Madrid; I. SANZ RubIALEs (2000), «El principio de confianza legítima como limitador del poder normativo comunitario», Revista de Derecho Comunitario Europeo, 7, págs. 91 ss.

La STS de 15-4-02 indica que este principio, «relacionado con los más tradicionales, en nuestro ordenamiento, de la seguridad jurídica y la buena fe en las relaciones entre la Administración y los particulares, comporta, según la doctrina del TJCE y la jurisprudencia de esta Sala, el que la autoridad pública no pueda adoptar medidas que resulten contrarias a la esperanza inducida por la razonable estabilidad en las decisiones de aquélla, y en función de las cuales los particulares han adoptado determinadas decisiones. O, dicho en otros términos, la virtualidad del principio que se invoca puede suponer la anulación de un acto de la Administración o el reconocimiento de la obligación de ésta de responder de la alteración (producida sin conocimiento anticipado, sin medidas transitorias suficientes para que los sujetos puedan acomodar su conducta y proporcionadas al interés público en juego, y sin las debidas medidas correctoras o compensatorias) de las circunstancias habituales y estables, generadoras de esperanzas fundadas de mantenimiento (Cfr. SSTS de 10-5, 13 y 24-7-99 y 4-6-01). Pero ello en el bien entendido de que, no pueden apreciarse los necesarios presupuestos para la aplicación del principio invocado en la mera expectativa de una invariabilidad de las circunstancias, y que ni el principio de seguridad jurídica ni el de la confianza legítima garantizan que las situaciones de ventaja económica que comportan un enriquecimiento que se estima injusto deban mantenerse irreversibles». Vid. asimismo las de 13-5-09, 9-7 y 20-9-12. La de 27-6-13 indica que el principio protege los casos en que la actuación administrativa produce una apariencia de legalidad, que induce a realizar gastos e inversiones que luego no concuerdan con la verdadera voluntad de la Administración y sus consecuencias. En nuestro caso, por lo demás, el expropiado no experimenta ningún enriquecimiento injusto; al contrario. 
Pueden producirse distintas situaciones. La más clara es aquella en que, habiendo quedado unos terrenos fuera del deslinde, su titular registral los enajena a título oneroso a un tercero de buena fe; que por tanto debe quedar protegido por el artículo $34 \mathrm{LH}$, ya que en estos casos no suele ser evidente el carácter demanial de los terre$\operatorname{nos}^{88}$. Pero pueden darse otras. Por ejemplo, los bienes que quedan fuera del deslinde no se hallaban inscritos a nombre de ningún particular; pero finalmente un tercero los adquiere y consigue su inmatriculación. Aquí no jugaría el artículo 34 LH, pero sí el principio de inoponibilidad - arts. 32 LH y $606 \mathrm{CC}$ - ya que ese tercero no puede verse perjudicado por títulos no inscritos en el Registro y la Ley 2/13 ha clarificado el carácter obligatorio de la inscripción; además de que en estos casos se exige certificación administrativa previa a la inmatriculación ${ }^{89}$. O, también, la del titular registral cuyos bienes se excluyen del deslinde; o la de sus herederos, que incurren en obligaciones tributarias y en gastos cuando aceptan la herencia. O la de quien no era titular registral pero finalmente inmatricula los bienes a su favor. $\mathrm{O}$ podemos plantear el caso de un deslinde ya practicado, pero no inscrito.

Que estas situaciones merezcan protección deriva del artículo 15 LC y del RC; por mucho que el deslinde tenga efectos registrales conforme al artículo 13 LC. En efecto, si ésta y el RC exigen tomar nota marginal mientras se tramita el deslinde, y exigen su anotación hasta que transcurra el plazo de cinco años indicado por el artículo 14, es porque puede producirse un conflicto entre deslinde y Registro; y el modo de minimizarlo estriba en conferir publicidad registral al deslinde. Pero esto se debe a la necesidad de proteger la seguridad del tráfico inmobiliario, interés público de primera magnitud que se ve severamente afectado si la Administración puede modificar el deslinde por haber cometido omisiones en el deslinde previo, y ello no se acompaña de compensación más allá del otorgamiento de concesión.

Es cierto que el TEDH ha rechazado la infracción del artículo 1 del Protocolo en casos en que la demanda se basaba en un error previo de la Administración, por lo que no se había vulnerado un derecho previo

88 En Yildirir, el demandante era un tercero que había adquirido los bienes de otro que constaba como titular legítimo en el Registro. Las construcciones fueron finalmente demolidas por razones ambientales. A pesar de concurrir un interés público cualificado, como es la protección del medio ambiente, se entendió vulnerado el derecho de propiedad, ya que no se concedió al demandante indemnización alguna.

89 Desdentado Daroca (2007: 58) se plantea el caso de zonas no deslindadas, donde existan títulos inscritos en el Registro y terceros adquirentes de buena fe. Señala que esos terceros se hallan en una difícil situación generada por la pasividad de la Administración. 
sobre los bienes ${ }^{90}$. Sin embargo, estos supuestos nada tienen que ver con el nuestro. Así, en Pekinel se había inscrito en el Registro un bien con una superficie en 1884; la cadena de transmisiones amparadas registralmente venía referida, pues, a esa superficie y no a la mayor que el Tesoro había después inscrito a su favor. Así, no se había probado un derecho de propiedad sobre toda la superficie. Y en Özden ni siquiera existía una legítima expectativa sobre la propiedad ${ }^{91}$.

Pero, además, el TEDH exige que las injerencias sobre la propiedad sean previsibles ${ }^{92}$. Y no se puede considerar previsible la inclusión en un posterior deslinde de bienes excluidos de otro anterior, sin haber mediado cambios normativos ni en la configuración de la costa y sin que la LC contemple esta posibilidad; cuando, como será lo normal en estos casos, no resulte evidente que dichos bienes reúnan las características propias del demanio marítimo-terrestre ${ }^{93}$.

90 Lo recuerda la STEDH Köktepe: «El Tribunal señala ante todo que, en las sentencias invocadas por el Gobierno, los tribunales internos estimaron que las inscripciones en los registros de la propiedad que habían causado un perjuicio a los titulares de buena fe de títulos de propiedad eran la consecuencia de un "error", aunque éste no resultase de una equivocación del funcionario del Estado; ahora bien, en el presente caso, no hay pruebas de que el título de propiedad del demandante o de los anteriores propietarios desde 1953, se otorgase como consecuencia de un error. Las partes no discuten que en 1953 el erario público vendiese el terreno en litigio como terreno agrícola a un particular, y que el demandante fuese el quinto propietario en comprarlo, lo que hizo fiándose del Registro de la Propiedad que no mencionaba su calificación de monte de dominio público. Los tribunales internos rechazaron la demanda del interesado en cuanto a la delimitación sobre la base de las pruebas recogidas durante el procedimiento, no debido a un acto viciado de error cometido por funcionarios de la Administración, quienes en 1953 calificaron el terreno de agrícola, sino habida cuenta de las disposiciones legislativas aplicables en la materia».

91 El terreno se había adquirido al Estado. En 1968 se declaró forestal; lo que implicaba la inviabilidad de apropiación privada. La decisión queda firme en 1970, al no recurrirse; pero el bien siguió registrado a nombre del adquirente al no haber presentado el Estado demanda civil en aquel momento. En 1985 comienzan las negociaciones entre el actor y su causante para la compra. Como el Estado ya había iniciado procedimientos para inscribir el bien a su nombre, el demandante participó en ellos antes de formalizar la adquisición, que inscribe en 1989; y pudo defenderse. Se anuló judicialmente la declaración del terreno como forestal, pero la sentencia fue revocada. Finalmente, el bien se inscribió como terreno forestal público. Para el TEDH, no existía siquiera expectativa legítima sobre la propiedad del bien, ya que éste, en 1968, mucho antes de la adquisición, había sido declarado terreno forestal; lo que el actor conocía.

92 Véase, por ejemplo, Hentrich contra Francia, donde la estimación de la demanda se basa en que la ley confería un margen de discrecionalidad a la Administración que hacía difícilmente previsible su actuación; aunque asimismo se tuvo en cuenta la infracción de la igualdad de armas. Vid. Barcelona Llop, «Privación...», cit., pág. 80.

La STEDH Ucieza indica que la inscripción de la certificación del Obispado se había llevado a cabo de forma "arbitraria y nada previsible». "Según se ha aplicado en este caso el artículo 206 de la Ley Hipotecaria, no satisface de manera suficiente las exigencias de precisión y de previsibilidad que implica la noción de Ley en el sentido del Convenio». Podemos preguntarnos en qué medida puede calificarse de "previsible» la inclusión en un deslinde de costas de unos bienes excluidos de otro previo, sin que hayan mediado cambios físicos ni normativos; cuando la Ley 22/88 establece que estos cambios constituyen el presupuesto de hecho de la potestad de deslinde.

93 Más aún, el TEDH, en ocasiones, afirma que las expectativas legítimas pueden asimismo tener amparo en el artículo 1; así, en Oneryildiz: «la noción de bienes no se limita a 
En suma, aunque por hipótesis no se entienda lesionada la propiedad cuando se revisa un deslinde con inclusión de nuevos bienes antes excluidos, en estos casos existe una actuación imprevisible de los poderes públicos que vulnera la confianza legítima de quien de buena fe, en el ínterin, ha adquirido terrenos del titular registral; ya que normalmente no serán evidentes a simple vista las características naturales del demanio marítimo-terrestre, ni aun tras el estudio que originó el primer deslinde. Y esa infracción de la confianza legítima exige una indemnización adicional ${ }^{94}$.

Similar conclusión podría extraerse si los bienes se hubieran incluido en un deslinde al tiempo de la adquisición, sin que el mismo aparezca en el Registro ni haya constancia mediante nota marginal de un deslinde en curso. En otros casos, así el propietario cuyo terreno se excluye del deslinde y después ve frustradas sus expectativas por otro posterior, también en ocasiones puede verse lesionada la legítima confianza; por ejemplo, si hubiera realizado obras amparadas por título administrativo, sobre todo si son costosas y de difícil amortización en el plazo concesional ${ }^{95}$.

Si no ha habido operaciones de tráfico inmobiliario ni gastos adicionales - como pasa con el propietario que, sorpresivamente, ve incluido su terreno en el nuevo deslinde, sin concurrir cambios físicos ni normativos-, existiría una infracción abstracta de la seguridad jurídica, título más endeble para solicitar una indemnización adicional a la concesión.

los bienes actuales, y puede asimismo abarcar valores patrimoniales y creencias en virtud de las cuales el recurrente puede pretender tener al menos una esperanza legítima y razonable de obtener el goce efectivo de un derecho de propiedad» — vid. BARCELONA Llop (2011: 59 ss.)-. Así, aunque se considerara que los bienes se expropian ope legis u ope Constitutionis, de modo que ya no serían propiedad privada al tiempo del deslinde, este dato no sería relevante a la vista del concepto amplio de bienes que subyace al Protocolo; a lo que se añade que en su día habrá existido muchas veces, en origen, una adquisición legítima de la propiedad. En nuestro caso, existirá además una expectativa y una creencia legítima, basada en la previa actuación del Estado al haber excluido previamente el terreno del deslinde.

94 La misma solución es aplicable a la inmatriculación por el adquirente, dada la exigencia de certificación administrativa de que los terrenos no son demaniales.

Es cierto que con esta posición podría entenderse que se concede mayor protección a aquel cuyo terreno desde el principio poseía las características propias del dominio público, que a aquel que se hallaba en una situación diferente pero se ve sorprendido por un cambio normativo o en la configuración de la costa. Sin embargo, se podría entender que no existe el deber jurídico de soportar el daño causado por un error de la Administración; cuestión ésta sobre la que volveremos. De cualquier forma, el distinto tratamiento de uno y otros supuestos hace que surjan serias dudas sobre la suficiencia en general de la concesión compensatoria.

$95 \mathrm{O}$ pensemos en el heredero que paga el impuesto de sucesiones por la adquisición de la propiedad y después vea ésta transformada en concesión; aunque en este caso lo procedente es la devolución de ingresos indebidos. 
VI. POSIBLES SOLUCIONES: EN PARTICULAR, LA REVISIÓN DE OFICIO DEL DESLINDE PREVIO O LA DETERMINACIÓN DE LA INDEMNIZACIÓN EN EL ACTO QUE RESUELVE EL PROCEDIMIENTO DE MODIFICACIÓN

Hemos visto que la exclusión inicial de un terreno del deslinde, y su inclusión en otro posterior sin mediar cambio físico ni normativo, al menos puede vulnerar en ciertos casos la legítima confianza; lo que exige indemnizaciones adicionales a la concesión. Ahora bien, para llegar a esta conclusión, es preciso analizar la responsabilidad patrimonial por actos administrativos ilegales ${ }^{96}$; y plantear el procedimiento a seguir para determinar la indemnización ${ }^{97}$.

1. El deber jurídico de soportar el daño causado por ciertos actos administrativos ilegales: una crítica a la doctrina del margen de tolerancia

\section{A) Consideraciones generales}

Cuando se pide responsabilidad por daños derivados de acto administrativo ilegal, el TS entiende que, aunque haya daño económicamente evaluable, individualizado y efectivo, causado por aquél, muchas veces existirá deber jurídico de soportar el daño. Para ello utiliza la tesis del "margen de tolerancia», que pretende basarse en el artículo 32-1 de la Ley 40/15, que afirma que la mera anulación del acto no comporta por sí sola el derecho a indemnización ${ }^{98}$.

96 Desde otro punto de vista, Revuelta Pérez y Narbón Lainez (2010: 1629 ss.) entienden, para el supuesto del adquirente de buena fe cuya licencia es anulada, que podría haber responsabilidad del Estado por la defectuosa información existente en el Registro. En nuestro caso, posiblemente no haga falta recurrir a esto; ya que existen otros títulos de imputación, aunque todos converjan en la infracción de la legítima confianza.

97 Podría pensarse que, cuando el bien se ha enajenado en el período entre ambos deslindes, el adquirente podría acudir a acciones civiles, como la evicción o la anulación del contrato por error. Sin embargo, resaltan en otro contexto REvUELTA PÉREz y NARBón LAINEZ (2010: 1628 ss.) que la acción de anulación puede haber caducado. Además, la misma no obsta a que también pueda exigirse responsabilidad al Estado. El saneamiento por evicción, además, exige previa sentencia firme; lo que obligaría al adquirente a litigar contra el deslinde.

98 Vid. M. A. Muñoz GuiJosa (2015), "Sobre el requisito de la antijuridicidad en la responsabilidad patrimonial por anulación de acto administrativo», REDA, 168, págs. 145 ss.; la autora, op. cit., pág. 151, cita algunos casos en que se ha prescindido del criterio del margen de tolerancia. Asimismo, L. Medina Alcoz (2005), La responsabilidad patrimonial por acto administrativo. Aproximación a los efectos resarcitorios de ilegalidad, la morosidad y la deslealtad desde una revisión general del sistema, Civitas, Madrid. 
Del precepto no se deducen las conclusiones que extrae el TS. Lo que significa el artículo 142-4 de la Ley 30/92 —actualmente, art. 32-1 de la Ley 40/15- es que en ocasiones no concurre daño efectivo causalmente conectado con la ilegalidad del acto; y que en otras existe el deber de soportar el daño. Pero esto último no supone reconocer un margen de tolerancia. Esta doctrina viene a decir que, si se trata de potestades discrecionales o de aplicar conceptos indeterminados, la anulación del acto no siempre implica el derecho a indemnización: sólo si aquél resulta arbitrario o irrazonable. No basta que sea ilegal; es precisa una ilegalidad cualificada, ya que de otro modo existirá el deber de soportar el daño. Es más, el TS ha extendido esta doctrina al ejercicio de potestades estrictamente regladas; aun más allá de la aplicación de conceptos jurídicos indeterminados ${ }^{99}$.

Estas consideraciones poseen gran importancia para nosotros, porque el deslinde del demanio marítimo-terrestre exige apreciaciones técnicas complejas. Así, el hecho de que un deslinde no incluya terrenos que poseen las características del demanio no significa que esa omisión sea arbitraria o irrazonable; es más, normalmente gozará de apariencia de legalidad ${ }^{100}$.

99 Vid. Muñoz GuiJosa (2015: 148). La STS de 20-2-12 señala: «Incluso cuando se trate del ejercicio de facultades absolutamente regladas, procederá el sacrificio individual, no obstante la anulación posterior de las decisiones administrativas, cuando éstas se ejerciten dentro de los márgenes de razonabilidad que cabe esperar de una Administración pública llamada a satisfacer los intereses generales y que, por ende, no puede quedar paralizada ante el temor de que, revisadas y anuladas, en su caso, sus decisiones, tenga que compensar al afectado con cargo a los presupuestos públicos, en todo caso y con abstracción de las circunstancias concurrentes. En definitiva, para apreciar si el detrimento patrimonial que supone para un administrado el funcionamiento de un determinado servicio público resulta antijurídico ha de analizarse la índole de la actividad administrativa y si responde a los parámetros de racionalidad exigibles. Esto es, si, pese a su anulación, la decisión administrativa refleja una interpretación razonable de las normas que aplica, enderezada a satisfacer los fines para los que se la ha atribuido la potestad que ejercita. Así lo hemos expresado en la ya citada sentencia de 16-2-09».

Como resalta P. BoIX MAÑo (2012), «Responsabilidad patrimonial por anulación de actos administrativos (doctrina del margen de tolerancia), y por la adopción de medidas cautelares», Revista Española de la Función Consultiva, 18, págs. 19 ss., si estamos ante «elementos completamente objetivos» que se han infringido - número de habitantes a efectos de apertura de farmacias, cómputo del plazo de prescripción...- se entiende que existe responsabilidad patrimonial; pero ¿qué diferencia hay entre lo totalmente reglado y un elemento objetivo?

100 No obstante, MuÑoz GuIJOsa (2015: 153) se refiere a la STS de 10-5-12, que afirma que el deslinde de una vía pecuaria se había excedido del margen de tolerancia, al haber actuado la Administración indiligentemente. La de 24-1-06, en un deslinde anulado, reitera la doctrina general de acuerdo con la cual, cuando se trate de aplicar conceptos jurídicos indeterminados, existe deber de soportar el daño salvo que su interpretación haya sido irrazonable; lo que pretende justificar en que, en caso contrario, se paralizaría la actividad administrativa.

Para G. Doménech PAScual (2010), «Responsabilidad patrimonial de la Administración por actos jurídicos ilegales», RAP, 183, págs. 187 ss., esta doctrina puede tener sentido en autorizaciones donde exista un importante margen de apreciación por efectuarse juicios pros- 
A mi juicio, la doctrina del margen de tolerancia resulta errónea. Puede haber casos en que el perjudicado por el acto ilegal tenga el deber jurídico de soportar el daño. Ello sucede esencialmente si ese perjudicado hubiera incurrido en dolo, culpa o negligencia graves; como indica el artículo 35 TRLS para la anulación de licencias. Sin embargo, no existe base normativa para entender que concurre el deber jurídico de soportar el daño causado por un acto anulado - no por su anulación- a menos que la decisión administrativa resulte irrazonable o arbitraria.

En efecto, podría entenderse por hipótesis que una decisión no arbitraria ni irrazonable constituye un caso de funcionamiento normal ${ }^{101}$; pero también puede haber responsabilidad patrimonial en tales supuestos, si bien, a diferencia del funcionamiento anormal, podrá concurrir el deber de soportar el daño ${ }^{102}$. Pero que tal deber sea compatible con el funcionamiento normal no significa que concurra siempre que se dé esta circunstancia; porque ello implicaría negar la responsabilidad por funcionamiento normal. Además, es dudoso que un acto ilegal constituya por regla general un caso de funcionamiento normal ${ }^{103}$; el voto particular de PECES Morate a la STS de 5-2-96 afirma que no puede haber deber jurídico de soportar el daño causado por un acto ilegal.

Además, la teoría del margen de tolerancia adolece de indeterminación; ya que implica que los Tribunales, caso por caso, sean quienes indiquen si el acto es simplemente ilegal o, por el contrario, resulta irrazonable o arbitrario. Así, el derecho a indemnización dependerá de que un órgano jurisdiccional considere que la infracción legal es evidente y manifiesta o no; apreciación donde existe un importante margen de subjetividad ${ }^{104}$. La inseguridad jurídica está servida: lo que

pectivos, como la farmacovigilancia o ciertas autorizaciones ambientales; pero no cuando se ejerciten potestades de gravamen. No obstante, la sentencia del Tribunal General Artegodan, que comenta el autor, fue casada por el TJUE; la reclamación por los daños causados por el acto anulado finalmente se desestimó, pero el TJUE entendió que el acto era conforme a Derecho en cuanto al fondo, aunque se había dictado por órgano incompetente — la STS de 8-5-07 entiende, no obstante, que procede indemnizar en un caso en que el acto se había anulado por incompetencia; también la de 30-6-14; afirma lo contrario la de 8-4-14, que utiliza la doctrina del margen de tolerancia y añade que no existía nexo causal con algunos daños-. Vid. también S. DíEz SASTRE (2012), "Culpa versus ilegalidad. De nuevo sobre el fundamento de la responsabilidad por acto administrativo", REDA, 153, págs. 63 ss., para quien la tesis del «margen de tolerancia» se fundamenta en la culpa; lo que critica.

101 Vid. Muñoz GuiJosa (2015: 147 ss.), quien entiende que ésta es la posición de la jurisprudencia.

102 Vid. M. a J. Alonso Mas y E. Narbón Lainez (2013), La responsabilidad por los daños causados en la ejecución de los contratos administrativos, Civitas, Madrid, págs. 65 ss.

103 En este sentido, vid. las acertadas consideraciones de MuÑoz GuIJosa (2015: 164).

104 BoIX MAÑo (2012: 19 ss.) cita la STS de 16-9-09, que afirma el derecho a indemnización, pese a la calificación inicial del núcleo de población a efectos de apertura de farmacias como concepto jurídico indeterminado. Subraya la autora que el asunto era perfectamente objetivable, ya que la solución se desprendía de la simple lectura de un plano. 
es irrazonable para un órgano jurisdiccional puede no serlo para otro. La concurrencia del deber de soportar el daño no puede dejarse en manos de cada decisión judicial, en ausencia de datos normativos. Si un órgano judicial ya ha anulado el acto, y de éste se derivan daños, éstos deberán indemnizarse; salvo que exista dolo o negligencia graves del perjudicado $^{105}$. La doctrina del margen de tolerancia, además de carecer de base legal, conduce a la inseguridad jurídica.

Es más, podría entenderse que, aun en el funcionamiento normal, el deber de soportar el daño exista sólo cuando derive explícita o implícitamente de una norma; lo que no sucede en nuestro caso ${ }^{106}$. Nuestro Derecho sólo contempla explícitamente el deber de soportar el daño causado por acto administrativo si concurre negligencia, dolo o culpa graves imputables al perjudicado; lo que es del todo razonable porque depende de la conducta de éste ${ }^{107}$.

En suma, en el caso de acto ilícito la consideración de lo que es o no tolerable se traslada por el TS desde el sujeto que padece el daño hacia el comportamiento de la Administración. No importa que el daño sea desproporcionado — tesis del sacrificio especial ${ }^{108}$ — como más bien que la ilicitud del acto resulte evidente u ostensiblemente grave; lo que no tiene sentido. En efecto, en el funcionamiento normal, el deber de soportar el daño depende de que concurra lesión de derechos, o de su

105 Vid. Muñoz GuiJosa (2015: 159), quien con acierto señala que el criterio de la irrazonabilidad ya se ha tenido en cuenta al anular el acto; por lo que no puede volverse a considerar a efectos de la indemnización a favor de quien no ha participado en la comisión de la ilegalidad.

106 Para la STS de 18-12-00: «El deber jurídico de soportar el daño en principio parece que únicamente podría derivarse de la concurrencia de un título que determine o imponga jurídicamente el perjuicio contemplado, tal sería la existencia de un contrato previo, el cumplimiento de una obligación legal o reglamentaria siempre que de esta se derivasen cargas generales, o la ejecución administrativa o judicial de una resolución firme de tal naturaleza; esto que desde la perspectiva del funcionamiento de los servicios públicos aparece relativamente claro en su interpretación, se complica a la hora de trasladarlo a los supuestos de anulación de resoluciones administrativas».

107 En ocasiones se entiende que la cláusula del estado de la ciencia también refleja un caso de deber de soportar el daño. Vid. el voto particular a la STS de 31-5-99; ALONSO MAS y NARBÓN LAINEZ (2013: 62).

Tema distinto es que el acto se anule por vicio formal. En tal caso puede que, en su contenido, sea conforme a Derecho. BoIX MAÑo (2012: 19 ss.) alude a las SSTS de 13-12-11 y 202-12, anulación de actos de una Confederación Hidrográfica por falta de motivación y del trámite de audiencia general; si bien es dudoso que la falta de motivación constituya en todo caso un mero vicio formal. En caso de caducidad del procedimiento de deslinde, difícilmente podríamos hablar del deber jurídico de soportar el daño: vid. STS de 10-4-12, sobre caducidad de procedimiento sancionador; en sentido contrario, MuÑoz GUIJOSA (2015: 163) cita la STS de 29-7-13. La de 23-6-15 rechaza la responsabilidad patrimonial en un caso de caducidad del deslinde; pero porque dicha responsabilidad ya se había enjuiciado con anterioridad en sentido desestimatorio. La sentencia no descarta que en estos casos pueda existir responsabilidad; pero aprecia que en el enjuiciado no existía relación causal.

108 Entre otras, STS de 23-3-09. 
carácter desproporcionado; pero, en los casos de acto ilícito, el TS se olvida de ello. Todo depende, dice el TS, del margen de decisión de la Administración y del carácter flagrante o no de la infracción; el fin es evitar la parálisis administrativa por el miedo a tener que indemnizar ${ }^{109}$.

\section{B) La distinción entre los daños causados por el acto anulado y los daños causados por la anulación del acto}

Ya he criticado la doctrina del margen de tolerancia; que incluso menor sentido tiene, si cabe, en caso de nulidad de pleno derecho. Pero, además, cuando estamos ante la anulación de un acto, hay que distinguir los daños causados por el propio acto ilegal y los derivados de su anulación.

Rechazada la teoría del margen de tolerancia, no hay duda de que el perjudicado por un acto anulado debe ser indemnizado. Imaginemos que se acrediten daños a la salud debidos a los ruidos causados por una actividad amparada en una licencia después anulada. El daño tiene por causa el otorgamiento ilegal de la licencia; y existe lesión indemnizable.

$\mathrm{El}$ otro caso es aquel en que el particular resulta beneficiado por el acto; y después éste se anula. En tal supuesto, el perjuicio no lo produce el acto ilegal y anulado; es su anulación la que lo causa ${ }^{110}$. Aquí puede concurrir el deber de soportar el daño. Pero no es preciso, normalmente, recurrir al margen de tolerancia; simplemente, el particular se ha beneficiado por un tiempo del acto ilegal y no tiene sentido como regla general que se le compense por su retirada, al no tener derecho a su mantenimiento. Lo normal es que concurra el deber de soportar el daño.

No siempre es así, no obstante. Puede que el acto haya generado unas expectativas; y que a consecuencia de las mismas se realicen gas-

109 Es decir, esta doctrina se aproxima a la exigencia de violación suficientemente caracterizada que establece el TJUE para la responsabilidad estatal por infracción del Derecho de la Unión; sin embargo, la STJUE Norwood, considerando el principio de equivalencia, ya afirmó que los Estados miembros pueden establecer un régimen menos gravoso. Para E. Cobreros Mendazona (2015), «La exigibilidad del requisito de la violación suficientemente caracterizada al aplicar en nuestro Ordenamiento el principio de la responsabilidad patrimonial de los Estados por el incumplimiento del Derecho de la Unión Europea», $R A P$, 196, págs. 11 ss., si bien el principio de equivalencia vendría referido a los requisitos formales y no a consideraciones de fondo, de la jurisprudencia del TJUE se deduce que el Derecho de la Unión sólo establece un mínimo común denominador en la materia, mejorable por los Estados miembros; por lo que (2015: 52) concluye que el requisito de la violación suficientemente caracterizada no es exigible en nuestro Ordenamiento cuando se trata de responsabilidad de la Administración por incumplimiento del Derecho de la Unión. Véase, no obstante, el artículo 32-5 de la Ley 40/15

110 Por ejemplo, STS de 27-11-12. 
tos que devengan inútiles con la anulación del acto. En este caso, sí puede tener sentido la doctrina del margen de tolerancia - aunque la denominación no es adecuada-111; en el sentido siguiente: si el acto no goza de apariencia alguna de legalidad, si su ilegalidad es flagrante, no habrá podido generar expectativas legítimas cuando su destinatario haya empleado una diligencia mínima ${ }^{112}$. En cambio, si la ilegalidad no es evidente, el acto generará una expectativa de permanencia; y en ocasiones se habrán realizado inversiones que luego devienen inútiles ${ }^{113}$. Lo dicho sobre el destinatario es, con más motivo, aplicable al adquirente de buena fe, que ha invertido en la adquisición del bien confiando en la legitimidad del primer acto ${ }^{114}$.

Puede entenderse que, tanto al propietario del bien al tiempo del primer deslinde como al adquirente de buena fe, el perjuicio no se lo provoca el primer deslinde, sino su modificación posterior e inclusión ex novo de sus terrenos, que es el acto que materializa la defraudación de su confianza ${ }^{115}$. Serían, pues, aplicables las consideraciones anteriores.

111 Precisamente, la STS de 8-2-12, que MuÑoz GuIJOsa (2015: 151) señala como ejemplo en que se prescinde de la teoría del margen de tolerancia, resuelve en sentido estimatorio un supuesto en que el daño, según afirma la sentencia, no derivaba de los actos de ejecución del fallo anulatorio, sino del acto anulado.

112 Ello muchas veces exigirá que la ilegalidad sea asimismo evidente para un lego en Derecho, a menos que las circunstancias del beneficiado por el acto ilegal exigieran un canon de diligencia más elevado - una gran empresa con un plantel de asesores jurídicos y técnicos, por ejemplo.

Recordemos, además, que para la doctrina civil la exigencia de buena fe amparada en el artículo 34 LH no sólo equivale a ausencia de dolo, sino también a una razonable diligencia. Vid. SSTS, Civil, de 12-1-12 y 19-5-15, que consideran inexigible una diligencia extrema: «la carga básica de la diligencia exigible al adquirente no puede medirse o extenderse con relación a cualquier posesión o indicio de la misma que se hubiera debido o podido conocer, sino solo a una situación posesoria clara y manifiesta que se ejercite en concepto de dueño y que, por tanto, contradiga o ponga en seria duda la exactitud de la información registral, con relación al derecho inscrito».

113 La STS de 18-5-10 estima la reclamación de responsabilidad de la empresa a la que se concede por doble silencio autorización de instalación de un parque eólico; autorización por doble silencio luego anulada. Para el TS, existe derecho a indemnización dada la absoluta pasividad de la Administración; por lo que no podía decirse que ésta hubiera actuado dentro del margen de tolerancia. Se indemnizaron los gastos en la realización del proyecto de ejecución.

114 En realidad, tampoco es inadecuado entender que, en estos casos en que se ha vulnerado la legítima confianza, es en realidad el acto anulado el que causa el perjuicio; ya que ese acto ha generado la legítima confianza indebidamente, por lo que el acto que lo anula se limita a constatar que esa confianza nunca debió haberse generado. La posición expresada en el texto, sin embargo, es más clara porque permite acotar debidamente los supuestos en que sí puede entrar en juego la doctrina del margen de tolerancia.

Si entendiéramos que se lesiona la propiedad, por ser insuficiente la indemnización consistente en su transformación en concesión, nos encontraríamos con que el acto que causa el daño es asimismo el segundo deslinde, que es el acto que hace efectiva la expropiación sin indemnización suficiente.

115 Así, SAN de 30-3-15, que desestima la reclamación. En su día se emite informe por Costas, que indicaba que los terrenos se hallaban en zona de servidumbre de protección; el afec- 
Es cierto que nuestro caso presenta peculiaridades, ya que el primer deslinde, que excluye sus terrenos, normalmente no altera su situación jurídica: la alteración se produce por la modificación del deslinde e inclusión de sus terrenos. Pero el primer deslinde genera la creencia legítima de que los terrenos no eran demaniales, que se ve defraudada si ese primer deslinde es complementado por el segundo. La expectativa se generó por las omisiones o insuficiencias del primer deslinde; pero la situación es similar cuando el primer acto es ilegal por omisión relativa, como si lo es por haber incluido positivamente cláusulas ilegales.

Puede citarse la SAN de 10-7-13. Existía un deslinde anterior a la LC; pero también actuaciones posteriores de la Administración estatal, de las que se colegía que ese deslinde se adecuaba a la misma. Así, se emitió informe favorable a una serie de actuaciones urbanísticas; a resultas de lo cual el demandante realizó inversiones, en gran medida luego frustradas por el nuevo deslinde. La sentencia entiende que concurre responsabilidad; ya que además, al estar los terrenos en zona de servidumbre, no existe concesión compensatoria ${ }^{116}$.

\section{El procedimiento para la determinación de la indemnización}

Debemos partir de la jurisprudencia del TEDH. En Köktepe afirma que vulnera el derecho a un recurso efectivo deferir al demandante,

tado realizó obras y gastos, y después el terreno se incluyó en el deslinde. Entiende la sentencia que el daño no fue causado por el informe, sino por el deslinde posterior, conforme a Derecho. Se invocaba también la confianza legítima; pero se desestima por considerarse que el principio no se identifica con la simple expectativa en la invariabilidad de las circunstancias, y dado el carácter reglado del deslinde. Pero ni se han alterado las circunstancias, ni el carácter reglado significa que sea evidente la pertenencia de los terrenos al dominio público, ni implica la innecesidad de indemnizar. Otra cosa es que en el informe se hubiera hecho constar la inexistencia de deslinde posterior a la LC. La SAN de 30-3-15, sin embargo, se limita a decir que, como los deslindes se pueden revisar sin acudir a los artículos 102 ss. de la Ley 30/92 —actualmente, arts. 106 ss. de la Ley 39/15-, sólo existe una expectativa; con lo que se incurre en una petición de principio. En el sentido de la citada, la de 16-4-14; en un caso en que se había anulado el deslinde por razones formales, pero se estaba tramitando otro con el mismo contenido. La de 6-11-13 afirma que el daño causado por el deslinde no es antijurídico, porque el deslinde es una potestad reglada y de ejercicio debido; la del TS de 29-11-06 niega por ello la responsabilidad por la suspensión del otorgamiento de autorizaciones y concesiones debida a la incoación del expediente de deslinde. La STS de 18-7-12 rechaza la reclamación; pero porque el acto supuestamente generador de la legitima confianza era sólo la demarcación provisional de la línea del deslinde entonces en tramitación. En ese caso, además, había cambiado la configuración física de la costa.

116 La SAN de 22-4-10 desestima el recurso: se había adquirido la vivienda con base en la información dada por Costas; pero en el informe se afirmaba que el tramo estaba pendiente de deslinde, del que podía resultar la inclusión en el demanio; además de que hubo sentencia civil anulatoria del contrato. La de 5-11-08 desestima, pero porque del contenido del informe vinculante no se desprendían las consecuencias pretendidas por el actor. 
que ha sufrido ocho años de pleitos, a un ulterior procedimiento de responsabilidad patrimonial ${ }^{117}$. De hecho, la sentencia invoca la previa STEDH Guillemin, que considera lesionado el derecho de propiedad por la tardanza excesiva en indemnizar una expropiación ilegal; lo que debía afectar a la cuantía indemnizatoria ${ }^{118}$.

Podemos así entender que tampoco respeta las exigencias del derecho a un recurso efectivo deferir al demandante a un procedimiento ulterior de responsabilidad patrimonial tras la revisión del deslinde, que es lo que integra los bienes en el demanio. Por ello, sería razonable proceder primero a la revisión de oficio del previo deslinde que excluyó esos terrenos. Tal posibilidad se basa en el artículo 9 LC, que declara nulos de pleno derecho los actos que reconocen titularidades privadas en el demanio marítimo-terrestre. La resolución estimatoria de la revisión de oficio declararía la nulidad parcial del previo deslinde, por haber excluido esos terrenos; y habilitaría para complementar el deslinde.

En efecto, conforme al artículo 106-4 de la Ley 39/15, la resolución estimatoria de la revisión de oficio puede, en su caso, reconocer las indemnizaciones pertinentes. Así, el afectado vería reconocida su indemnización con anterioridad al nuevo deslinde; sin que se vulnere el derecho a un recurso efectivo, al no existir una remisión a un ulterior expediente de responsabilidad patrimonial tras el acto que materializa la privación del derecho de propiedad.

Es cierto que, como hemos visto, GonzÁLEz SALINAS ${ }^{119}$ entiende que la revisión de oficio sería inútil, ya que el Consejo de Estado poco tiene que decir sobre los aspectos técnicos del deslinde; a lo que se puede añadir que la imprescriptibilidad del dominio público haría inútil la alegación del artículo 106 de la Ley 30/92 —actual art. 110 de la Ley 39/15- Sin embargo, esto no obsta al deber de indemnizar; y la indemnización no puede deferirse a un ulterior procedimiento de responsabilidad patrimonial de resultado incierto. A mi juicio, el artículo 102-4 de la Ley 30/92 — actual art. 106-4 de la Ley 39/15- permite determinar, cuando se declara la nulidad vía revisión de oficio, no sólo la indemnización por los daños causados por el acto declarado nulo,

117 Vid. Revuelta Pérez y Narbón Lainez (2010: 1625 ss.). Es verdad que en nuestro caso hablamos de indemnización por lesión de la legítima confianza y no del derecho de propiedad; pero la solución no tiene por qué ser distinta desde la perspectiva del derecho a un recurso efectivo. Además, en Köktepe se afirma que aún no se había hecho efectiva la privación de la propiedad.

118 Posiblemente aquí se habla de lesión del derecho de propiedad, y no simplemente del derecho a un proceso justo, porque se parte de la premisa de la ilegalidad de la expropiación.

119 (2000: 610 ss.). 
sino también por los producidos por su declaración de nulidad, cuando procedan. La aplicación de ese precepto a nuestro caso permitiría que la indemnización se determinara antes de hacerse efectiva la expropiación y posibilitaría su pago inmediato tras la aprobación del nuevo deslinde - que sólo podría practicarse una vez declarada la nulidad parcial, por omisión, del anterior-; de modo que no se incurriría en los problemas apuntados en Köktepe.

Lege ferenda, podría modificarse la LC para permitir expresamente la modificación de los deslindes erróneos sin necesidad de revisión de oficio; pero en tal supuesto en el mismo acto de modificación deberían determinarse las indemnizaciones por infracción de la confianza. En todo caso, la solución no será muy distinta de la anterior, porque normalmente las indemnizaciones sobrepasarán el mínimo a partir del cual es preceptivo el dictamen del Consejo de Estado.

\section{CONCLUSIONES}

La doctrina jurisprudencial que permite la modificación del deslinde de costas que por error técnico no ha incluido un terreno tiene una base normativa discutible. Además, tal como se aplica, pone en entredicho la seguridad del tráfico inmobiliario y la confianza legítima; lo que es relevante si entre ambos deslindes se han llevado a cabo operaciones amparadas en el Registro o en las certificaciones expedidas por la Administración estatal. Ello, porque la concesión compensatoria no equivale al valor real de la propiedad, aunque tras la Ley $2 / 13$ haya aumentado su valor.

Frente a ello, es insuficiente aducir el carácter declarativo de los deslindes; estamos ante un acto definitivo que, en la medida en que excluye unos terrenos, crea una apariencia jurídica protegible. De ahí que las soluciones sean, o bien revisar de oficio el deslinde y determinar en ese momento la indemnización por lesión de la legítima confianza, o fijar esa indemnización en el acto de modificación de deslinde. Ni tiene sentido decir que la legítima confianza no se vulnera en estos casos, ni deferir al afectado a un futuro expediente de responsabilidad patrimonial, como se deduce de la STEDH Köktepe. Una cosa es que el terreno que posee las características propias del dominio público deba finalmente ser deslindado como tal; y otra la afectación a la confianza legítima.

Más difícil es afirmar que en estos casos se vulnere el derecho de propiedad; aunque, si se entiende que la LC no ampara la modificación del deslinde sin que hayan mediado cambios físicos ni normativos, el 
nuevo deslinde sería ilegal y, conforme a la doctrina del TEDH, la indemnización debería ser integral. En todo caso, ponderando la importancia que el TEDH otorga a la protección registral, quizá debería revisarse la doctrina del TC sobre la suficiencia de la concesión compensatoria. 
